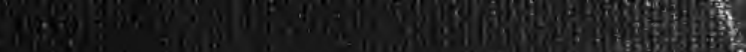

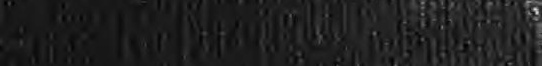




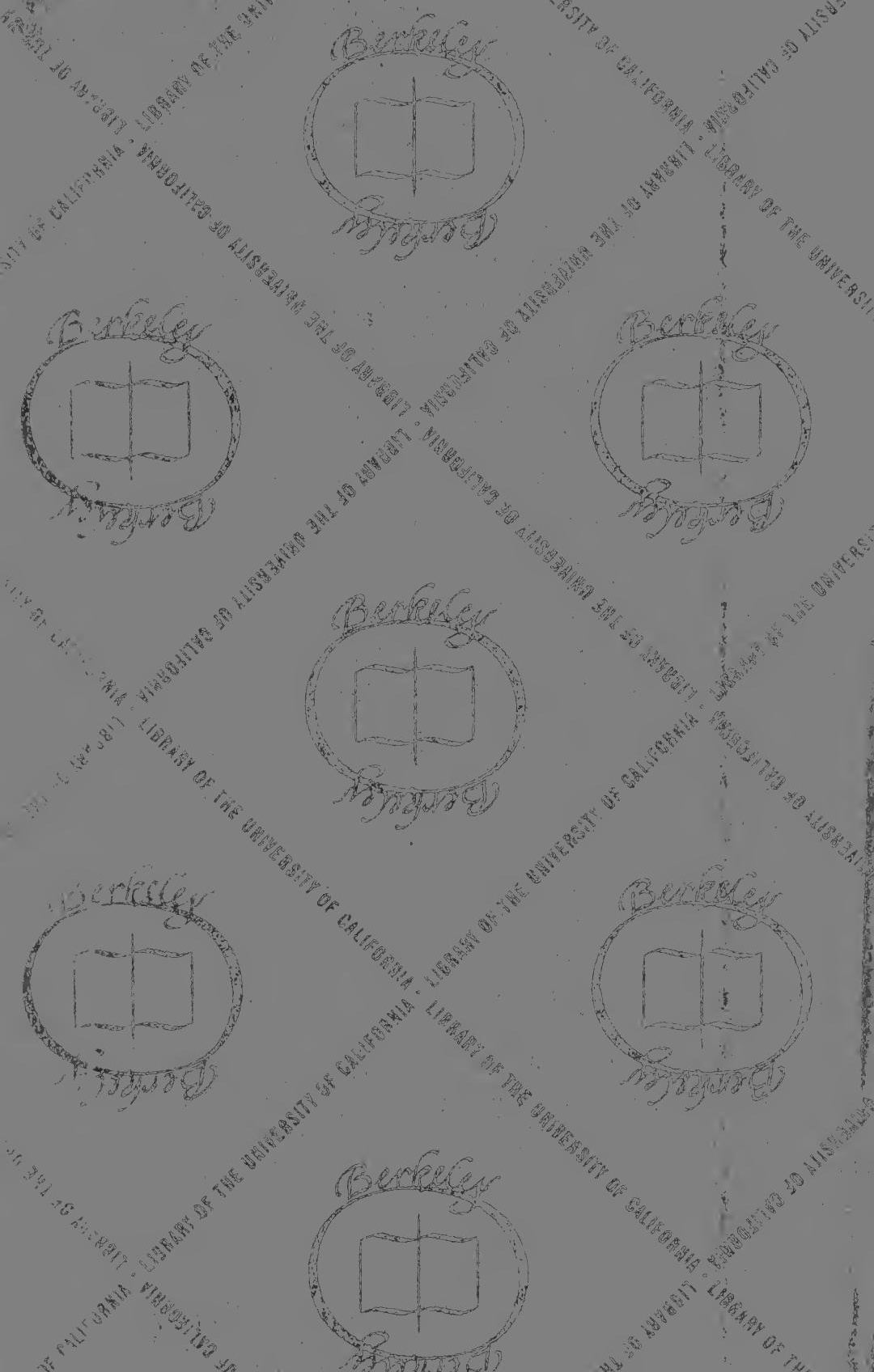



F

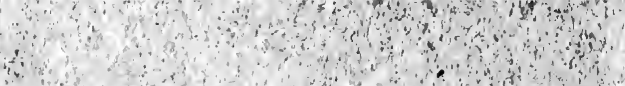

a

a

a

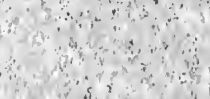

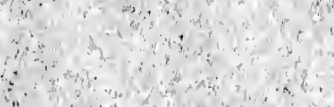

and

- 1.6

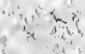



Digitized by the Internet Archive in 2007 with funding from Microsoft Corporation 


\section{THE ARGUMENT}

OF

\section{ARISTOTLE'S METAPHYSICS}

BY

EDITH HENRY JOHNSON, PH.D.

Hew york

LEMCKE \& BUECHNER, AGENTS

1906 


\section{$B 4=1$ J}

AFIERAL'

CoPyright, 19106,

BY

EDITH HENRY JOHNSON 


\section{To my siDotber}

$$
15825 \%
$$





\section{PREFACE}

This essay is the result of a study of Aristotle's Metaphysics undertaken in the history of philosophy seminar at Columbia University. The need for an acquaintance with Aristotle's own statement of his philosophical doctrine is generally recognized. To many students of philosophy, however, the difficulties presented by the original are almost insuperable. Yet, pending the appearance of an authoritative English translation, there seems to be no way of gaining an adequate appreciation of the Metaphysics except through recourse to the Greek text. Under the best of circumstances it will always remain a difficult task to master Aristotle's system of philosophy. The difficulty, it appears to the writer, is needlessly aggravated by obscurities in composition which prevent the student from centering his energies upon what is fundamental. In the following pages an attempt has been made to give without criticism a statement of what have appeared to one student to be the main currents of Aristotle's thought. In this attempt 
the Metaphysics is taken as an existing document, and no endeavor is made to enter into questions of historical origin and textual criticism.

In the preparation of this essay the author has been greatly indebted to Professor Frederick J. E. Woodbridge, of Columbia University, at whose suggestion the work was begun and under whose able direction it has been brought to completion. To Dr. H. B. Alexander, who has assisted with criticism and kindly advice, the author owes acknowledgment; and especially to her husband, Dr. Alvin S. Johnson, Adjunct Professor of Economics in Columbia University, she is indebted for invaluable aid and unfailing encouragement. New York City, June 15, 1906. 


\section{CONTENTS}

INTRODUCTORY ................. 11

\section{CHAPTER I \\ Preliminary Inquiries}

I. Nature and Origin of Scientific Thought . . . . . 21

II. Rank of Philosophy in the Hierarchy of the Sciences . . 23

III. Fundamental Objects of Philosophical Inquiry . . . . 26

IV. Manner and Method of Philosophical Exposition . . . 29

V. The Questions of the Book of Doubts . . . . . . 32

\section{CHAPTER II}

The Scope of Philosophy

-I. Philosophy as the Science of Existence as Such . . . 38

III. The Unity of Philosophy . . . . . . . . . . 39

III. Primal and Relational Existence . . . . . . . . . 44

IV. The Principles of Demonstration and Fundamental Concepts .............. . . 46

V. Philosophy and Theology . . . . . . . . 51

CHAPTER III

The Problem of Philosophy

I. The Possibility of Knowledge . . . . . . . . 54 
II. Discussion of Philosophical Concepts . . . . . . 59

III. Analysis of the Term Existence . . . . . . . . 62

IV. The True and the False . . . . . . . . . . 65

V. The Accidental ............ . 65

\section{CHAPTER IV}

Primal Existence

I. Diverse Views of Primal Existence . . . . . . . . 72

II. Matter . . . . . . . . . . . . 77

III. The Typical . . . . . . . . . . . 79

IV. The Definition . . . . . . . . . . 82

\section{CHAPTER V}

Primal Existence (Concluded)

I. Analysis of the Empirical Fact of Change . . . . . 90

II. Primal Existence as Matter and Form Combined in the Individual Object . . . . . . . . . . 99

III. Definition in its Relation to Primal Existence . . . . . 114

IV. The Universal . . . . . . . . . . . . 122

\section{CHAPTER VI}

The Unity of Matter and Form-Potentiality

I. The Statement of the Problem of Unity . . . . . . 132

II. The Logical Basis of Change . . . . . . . . . 140

III. The Unity of Individual Existence as Expressed in the

Terms of Actuality and Potentiality . . . . . 142

IV. The Actual and the Potential . . . . . . . . 146

V. The Primacy of the Actual .......... 153 
CHAPTER VII

The Ideas and Mathematical Entities

I. The Necessity for the Existence of the Eternal . . . . . 157

II. Mathematical Existence and the Pythagorean Doctrine . 160

III. Criticism of the Doctrine of Ideas . . . . . . . . 163

\section{CHAPTER VIII}

\section{Drvine Existence}

I. The Conception of a First Cause . . . . . . . 167

II. The First Cause as a Final Cause . . . . . . . . . 170

III. The Divinities of the Stars . . . . . . . . . . . . 177 IV. The Nature of God . . . . . . . . . . . 183 



\section{INTRODUCTORY}

To a few admirers of Aristotle it will forever appear an excellent thing that the discussion in the Metaphysics is variously interrupted and, without an always evident reason, frequently turned in new directions. In the same manner any good teacher might pause to repeat, to bring in historical example, to press home a point against opposing doctrine or to take up the argument from a new approach. But for the majority of readers the obscurities of the Metaphysics are undoubtedly increased by what appear as somewhat serious defects of composition. Aside from certain omissions and passages repeated or evidently misplaced, such as we should expect in an ancient writing, there is a lack of co-ordination among its various divisions which is almost certain to give rise to perplexity. It is for this reason that an attempt has been made to bring together in the following pages the main theses of the argument. Only a few indications occur in the text of the Metaphysics regarding its plan; and these on a first reading 
are easily overlooked. It may even appear that the work hardly forms a connected whole. The literary devices upon which the modern reader has grown dependent are lacking. The abrupt transitions and the frequent introduction of controversial matter tend to obscure the unity of the argument.

However many the indications that the Metaphysics, if it be essentially an integral, is at any rate an unfinished work, the judgment of incompleteness applies only in an editorial sense. Logically incomplete the Metaphysics is not. Its very defects of form indirectly disclose the completeness of its argument. That it has preserved through, we know not what historical vicissitudes, the unity which it undoubtedly possesses, is due wholly to the powerful structure of the original thought. Aristotle's argument has survived a measure of literary disintegration which would have been fatal to one not genuinely coherent. It can fail to impress no student of the text of the Metaphysics that, whatever interruptions the presentation may suffer, the thought is recovered with a firmness which would be impossible were it in fact less adequately conceived.

The confused impression which is likely to result from a first reading of the Metaphysics is not dismissed until one has learned to recognize those portions which 
are essential to the argument. In the form preserved from antiquity the work is divided into fourteen books, indicated by the letters of the Greek alphabet in their order from Alpha to $\mathrm{Nu}$ inclusive, the second division, however, being known as Alpha the Less, while the third book is Beta. Several of the books are in whole or in part of slight importance for the development of the argument. In fact, were the Metaphysics a modern philosophical writing, it is probable that the material would be so reduced as to represent only six of the fourteen books. The view has indeed been held that the Metaphysics is a collection of relatively independent and unfinished treatises. Upon a close examination of the text, however, this view does not appear to be tenable. It seems rather that we have in the body of the work a well connected argument, and that this is supported by discussions relating to the historical development of thought or devoted to the elaboration of concepts of which the argument makes use. While certain of the books are not essential to the statement of Aristotle's theory, the linkage is after all close. The recapitulations which are natural in view of the probable conditions under which the Metaphysics took its present form might readily be spared. But to dispense with large portions of the text would mean a distinct philosophical loss. 
It remains true, however, that a treatise might have been formed which would approach more nearly than does the Aristotelian work the modern standard of compact composition. While Aristotle's view will for different readers begin to take shape at various points, such a treatise would conceivably begin with what as the work.stands is the fourth division, Book Gamma. It would omit Delta, and from the beginning of Book Epsilon to the close of Theta would adopt the general procedure much as it is in the Aristotelian text. Neglecting Iota and Kappa, it would find the materials for its concluding chapters in Book Lambda. It is in Gamma that Aristotle gives his definition of philosophy or First Science and clearly marks out its subjectmatter. In Book Epsilon the province of what has been called the science of existence as such is further defined by the elimination of irrelevant meanings of the term existence. With the opening chapters of Book Zeta the problem is completely defined: What constitutes primal existence? Zeta gives the critical part of the argument. It is here that Aristotle tries the various modes of solving what he has stated to be the central philosophical problem and that his own definition of existence is finally reached. Between Books Zeta and Theta, Book Eta forms a natural link. It carries 
further the question raised in Zeta regarding the unity of form and matter in the individual or the concrete object, and suggests the answer in terms of the actual and the potential-conceptions which are fully developed in Theta. It is a principle of Aristotle's exposition that philosophical inquiry should begin with what is apparent to sense perception; thenceld pass, if possible, to reality beyond the reach of senseto the existence of the divine. Accordingly the earlier part of the Metaphysics is consistently devoted to the determination of what constitutes the existence of objects in ordinary experience. Upon the completion of this study the logical necessity of positing an existence beyond sense perception is indicated, and in Book Lambda Aristotle brings all the resources of - his philosophy to bear upon what he conceives to be the highest object of philosophical inquiry, the nature of the divine.

The plan of the present essay requires chief emphasis upon those portions of the Metaphysics which contain the more prominent indications of the movement of the argument. These portions, as has been indicated in the preceding paragraph, can be discussed with but slight departure from the order in which they stand in the text. Since, however, the books which are not actively occupied with the direct exposition of the 
theory do nevertheless contribute to its more complete elucidation, they can not be entirely disregarded. In many cases they afford indications concerning the motives underlying Aristotle's procedure, and elsewhere they complete inquiries which the main discussion has suggested but cannot pursue.

Book Alpha forms so admirable an introduction to the whole work that a modern presentation would hardly care to dispense with its tracing of the development of knowledge, its masterful characterization of the highest knowledge, or even with its obviously biased account of earlier philosophy. The second book is a brief one and consists largely of general remarks on method; but what is of more importance, it announces what is later to appear as a highly significant doctrine, viz. that no causal series whatever can be infinite. Book Beta passes in rapid summary the questions which historically have arisen or must naturally arise in the pursuit of the inquiry. As a result of the decision in Book Gamma to consider the study of general terms a proper part of philosophy, Book Delta records the detailed examination of about thirty concepts. It is more, however, than the glossary which its construction suggests ; it is genuinely philosophical in intention. The study of concepts recurs in Book Iota, which is 
chiefly occupied with unity and its derivative concepts. Iota is more detached than any other of the books, and yet the relation to the main development is probably more intimate than at first sight appears. When one considers the central position occupied in the chief inquiry by the concept of change, and its necessary implication, the concept of contraries, which in turn is made to depend upon the distinction between unity and plurality, the connection with the main argument is at least indicated. Kappa is of all the books of smallest special value. Aside from the very considerable doubt as to its right to a place in the Metaphysics, ${ }^{1}$ the fact that the first half is made up of repetitions from the other books, with negligible differences as to expression, while the latter half is largely quotation from the Physics, renders this division of slight significance. Books $\mathrm{Mu}$ and $\mathrm{Nu}$, on the other hand, form the most valuable commentary there remains from antiquity on the doctrines of Plato and the Pythagoreans. Owing to the preservation of Plato's Dialogues such a commentary cannot have the importance as regards the system of Plato that it has for the study of the Pythagoreans. Aristotle is supposed to have prepared a treatise upon

${ }^{1}$ Cf. Christ's edition of the Metaphysics, p. 218, 1059a, 18, note. 
the Pythagorean teachings, but as this has not survived we are largely dependent for their reconstruction upon the criticisms in the last two books, together with briefer comment occurring elsewhere in the Metaphysics. While Books $\mathrm{Mu}$ and $\mathrm{Nu}$ appear chiefly in the light of a criticism of the doctrines of the Ideas and mathematical entities, they serve also to bring out with some clearness Aristotle's own conception of number.

Refutation of opposing doctrine is of such common occurrence in the Metaphysics as to constitute one of Aristotle's most usual means of exposition.' No important position is taken without an endeavor to reach out against possible objection. Instances of this occur when in the course of developing the thesis that all that is real is concrete and individual, that there is an essential diversity in the world, repeated attacks are made on those who would advance the universals as the most genuine forms of existence, and especially on those who would reduce everything to Being or Unity; again, in defence of the plea for the acceptance of what is essential in demonstration and fundamental for knowledge, as against Protagoras and the followers of Heraclitus; once more in the answer to the Megarians, who had called in question the concept of potentiality. Again, after the inquiry has passed from what is sensibly per- 
ceived to the consideration of what may exist beyond reach of perception, and the conclusion is reached that there is a First Mover, who is one, Aristotle not only tests the belief in many supreme beings, but further enters upon an elaborate inquiry concerning other proposed existences beyond the realm of sense, the Ideas and mathematical entities. Reference to other thinkers is by no means always adverse, although it is improbable that Aristotle was himself fully aware of the extent to which he may actually have been indebted to them. In the main he follows his own precept, critically to observe what others have said in order that one may see wherein one may agree and wherein one must disagree with them. An interesting tendency exhibited in the Metaphysics is the endeavor towards a more or less psychological account of the origin of the views criticised, notably in the case of the theory of Ideas and of the doctrine of numbers. I It is of course now impossible to determine how far these analyses are correct, but they are at any rate full of suggestion.

Characteristic of the constructive work of the Metaphysics is the unceasing care to discriminate in any problem between the essential and the non-essential; and when the discrimination has been made, steadfastly to disregard in the pursuit of the inquiry the irrelevant 
and accidental-although never to deny its existence. No less pronounced is the tendency to introduce wherever possible the most concrete examples obtainable. The directness and lucidity of presentation is largely owing to these two facts. Aristotle announces as part of his method, to proceed from that which is less clear in itself, though early evident to sense perception, to that which is by nature most clear but difficult to recognize. The result of philosophy should be to attain that which in itself is the most transparent truth, the most unwavering and necessary. It is difficult only because "like birds of the night we are blinded by that which in its own nature is bright as the day." 


\section{CHAPTER I}

\section{Preliminary Inquiries}

The first three books of the Metaphysics constitute an introduction to the body of the work. Before undertaking a formal definition of philosophy, Aristotle offers a theory as to the origin of speculative thought and indicates its place in the development of knowledge. Apart from any possibly practical value, Aristotle observes, men desire knowledge for its own sake. That there is in all men a natural desire for knowledge on its own account he conceives to be indicated by the fact that the sense of sight is universally prized above the other senses. This is not merely because vision is the most useful of the senses. Entirely apart from practical motives, we place the highest value upon vision because we derive from it more knowledge than from any other sense. Vision makes evident more distinctions in the external world, and this is the reason why it is preferred. It may be said, then, that although the 
development and formulation of knowledge for its own sake is a late product of human activity, the need which it satisfies is nevertheless an important need experienced

+ by almost all human beings. Such bodies of knowledge as arise through the mere impulse to know, Aristotle calls the speculative or theoretical sciences. $\mathrm{He}$ later classifies these sciences as mathematics, natural science and philosophy.

Whenever sense perception does not of itself satisfy the desire to know, questions arise which can be satisfactorily answered only when many instances of a given kind have been observed. Facts must stand not isolatedly nor fortuitously joined as they do in sense perception, but must be grouped according to their kind. Mere generalization of observed fact is, however, not in itself sufficient. The inquirer is not content with the knowledge that one fact resembles another; he will not rest satisfied with the mere noting of likenesses and differences. When the observation of many instances of a class of phenomena leads to an investigation of their causes, knowledge becomes scientific.

Science builds upon empirical knowledge. Nevertheless science is not merely empirical knowledge; it is in a way independent, and the truer it is to its nature, the more complete is that independence. That 
is the higher science which covers the wider range of facts and which passes the farther from the concrete. The most thoroughly formulated knowledge, the highest science of all-First Science, Aristotle calls it-must be farthest from the ordinary knowledge of any particular fact, since it must take cognizance of every fact - since, Aristotle implies, the world and all contained therein is its province.

II

It follows then that in Aristotle's thought the rank of a science in the hierarchy of knowledge is not determined by its practical utility. A man's capacity for action bears no direct relation to his acquaintance with general truth. Action, Aristotle emphatically asserts, proceeds from the concrete to the concrete. In a particular situation where something is to be done, the man who has frequently confronted the same conditions may be counted upon to succeed, while one who has wide knowledge, but who has not been called upon to act under similar conditions, will most probably fail. Nevertheless we rightly hold in the-highest esteem the disinterested search for knowledge. It is because, as has been suggested, we are not purely practical beinge. If those sciences ranked highest which are most inti- 
mately related to action we should consider the merely clever practitioner superior to him who has the most comprehensive knowledge of the healing art. Now the one who has the widest knowledge can most clearly unfold the causes; he it is who is able to communicate his knowledge to others, and this is one reason we rank him highest. Moreover, he excels in that which is man's chief claim to superiority over other terrestrial beings - the ability to attain a knowledge of causes. ${ }^{1}$

As the end of practical endeavor is to make and to do, so the aim of philosophy is to know. Those who have a predominantly practical interest care for knowledge of causes only in so far as such knowledge bears immediately upon the accomplishment of some particular purpose. In the knowledge of causes as revealing truth, and especially in the knowledge of the highest causes or eternal principles as embodying

${ }^{1}$ Artistotle makes an interesting comparison between human and animal psychology, which brings out the fact that the desire for knowledge is, so far as may be discovered, possessed by man alone. Animal intelligence does not exbibit it. Knowledge builds upon experience, and experience is impossible without memory. Animals apparently possess memory in only a limited degree. Therefore it is to be presumed that it is impossible for them to attain to a perception of causes. 
the most complete truth, whence lesser truths are derived, the interest is purely philosophical.

Although the desire to know is pronounced by Aristotle to be a universal human trait, he observes that in the order of development those bodies of knowledge which exist to satisfy this desire appear only after the practical needs of mankind have been met. The cultivation of the reflective sciences presupposes leisure. Man must first have turned his attention to those facts the mastery of which was necessary for his existence. Of the various bodies of knowledge the first to develop, therefore, were probably those most intimately bound up with practical interests. It may be supposed that the knowledge upon which is based the art of building or of navigation, or the practice of medicine, must in some degree have been formulated at a very early time. Next to develop, Aristotle suggests, was the knowledge underlying arts ministering to the enjoyment of life, such, possibly, as music, poetry. Latest to become the subject of thought were the sciences which in no way contribute to material well-being, and which in distinction from the sciences pursued for practical ends may be called speculative or reflective. ${ }^{1}$ It was accord-

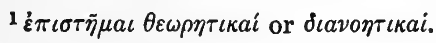


ingly natural that the speculative sciences, which may be regarded as the highest product of human activity, should first have been cultivated in that region of the earth where the practical needs were first fully provided, and where first there arose a class of persons freed from the care of procuring the means of material well-being. Thus the earliest development of mathematics appeared in Egypt among the priestly class. ${ }^{1}$

III

It is shown in the Physics that there are four fundamental types of question, the answers to which are technically known as causes. One may ask as the - ultimate questions concerning any object of inquiry, what is its essential nature; from what has it arisen; by means of what has it been brought into existence; and to what end does it exist? The answers are known respectively as the formal, the material, the efficient and the final causes. ${ }^{2}$ The four questions when

${ }^{1}$ Without testing the example which Aristotle has employed, it is necessary to observe the complete isolation which he gives the reflective life. The highest form of reflective thought, "First Science," or philosophy, is entirely without practical reference.

${ }^{2}$ aĩ translate it as "cause" is to incur the risk of its being identified with " efficient agent." This translation, however, has the sanction of usage, and another term could not well be substituted. 
developed in their widest possible significance constitute philosophical inquiry. Philosophy must as a science treat of causes, and as the highest science, must survey the highest or universal causes.

In the historical development of philosophy Aristotle measures progress according to the recognition given by the various thinkers to what he calls the primary "causes and origins." The object of the historical survey which is undertaken in the latter part of Book Alpha is quite evidently two-fold. Aristotle would exhibit his predecessors serving as unconscious witnesses of the validity and completeness of his formulation of the causes. He would, in other words, offer the claim that the recognition of the four types of cause was a natural development, which reason could scarce avoid. But of no less importance to the purpose in hand, he would show that the development was carried on by men who were by no means clearly aware of what they were doing. All the names which figure in the history of early Greek philosophy are introduced in approximately the usual chronological order ; and besides these there is mention of several thinkers who have now passed from notice. It is indicated that they developed the causes one by one, partially and often maladroitly. What the facts of the world announced in clearest tones 
they heard but indistinctly. The earlier thinkers failed to realize that all the four causes were absolutely essential to adequate explanation. They grasped the modes of explanation separately-one, two, or at most three; thence the incompleteness of their systems. And in the case of those they recognized, they had not so steady a vision as to preserve them from confusion; hence many of the positive errors of the early doctrines. Thus, all did not have a clear recognition even of the material cause ; some ignored the efficient cause or misconceived it ; few attained any idea of the formal cause ; nearly all who recognized the final cause confused it with the efficient, and no one had an abidingly clear conception of it. Aristotle likens the early thinkers to untrained fencers, who may make some fine strokes without knowledge of what they are doing.

The historical account of the causes contains nothing that is essential to Aristotle's argument. It has, however, exercised a great influence in the traditional presentation of early Greek philosophy, and for all but the more recent writing on the history of the period has constituted a powerful precedent. A closer scrutiny of the obtainable evidence as to what were the actual opinions of the philosophers in question has diminished the prestige of the Aristotelian account. It appears 
that Aristotle, comparatively near as he was in time to the period under consideration, had only a limited success in its reconstruction. Lacking the accuracy of an impartial historical account, the survey is evidently a synthesis controlled by a dominating interest.

IV

Of the value of comparing one's own views with those of others, Aristotle is strongly convinced. $\mathrm{He}$ says at the beginning of Book Alpha the Less that ne one can get at the whole of truth or miss it altogether, but all must contribute toward the complete explanation of nature. This is the reason we should give recognition not only to those whose opinions seem accordant with our own, but also to those whose investigations now appear as of slight value. If, for example, Timotheus had never lived, the progress in music would not be what it is, and without Phrynus, Timotheus would not have accomplished what he did. In the last chapter of the book there are some suggestions as to the method of presenting any doctrine. People. are prone to welcome that which comes in a familiar garb. Approval will vary according as some have been trained to require mathematical exactness, others concrete examples, while others will be captivated by sonorous phrases from the poets. But in all one at- 
tempts, he must take care not to confuse the method of presentation with the study of the subject-matter itself. The mathematically exact method, which some scorn even in scientific discussion as unworthy of a free soul, is indeed appropriate in a science where the material cause does not enter, but it is evidently inadequate for the study of nature in its entirety.

In the absence of all certain knowledge as to the conditions under which the Metaphysics received the form in which we know it, the construction of Book Alpha the Less will continue to give rise to much conjecture. ${ }^{1}$ Individually its three chapters show a more studied composition than any other chapters of the Metaphysics. Yet they fall together in such a way as to suggest that the grouping has been adventitious. While the first and third chapters consist of discussion on the method of conducting the inquiry, there appears in chapter two an exposition, given in more detail than seems consonant with the decidedly general character of the book as a whole, of the necessity that in every causal series there is an absolutely first term as there is an absolutely last term. Infinite regress ${ }^{2}$ is by specific arguments

1The authenticity of the book is doubtful. Cf. Christ's edition, p. $35,993 \mathrm{a}, 28$, note.

${ }^{2} \tau \grave{o} \beta a \delta i \zeta \varepsilon \iota v \varepsilon i \zeta$ ă $\pi \varepsilon \iota \rho o v$. 
debarred from the conceptions of the material, the efficient, the final and the formal cause. In the infinite all alike are middle terms; there is no first term, there is strictly no cause of any kind. In any mode of production the material cause is not exhaustless, nor the agency capable of being ceaselessly shifted from one term to a new one; in any effort at definition the factors which serve to define are not indefinitely resolvable; and in no action is the aim capable of incessant transmutation. Were it so, there would strictly speak ing be no aim, and no definiteness in the constitution of things. Rationality could not have appeared in the world and science would have been impossible, for science depends absolutely upon definiteness in conceptions and determinate sequences in things. Even were it otherwise, were causes in fact infinite, knowledge of causes would nevertheless be unattainable; for how in a limited time could the mind exhaust infinite series of causes? If this chapter is viewed in the light of the discussions that are to follow, it no longer appears as of so special a character as not to belong in the body of the work. Wherever in later argument an infinite series of causes begins to emerge there is an immediate condemnation of the position. In Aristotle's judgment the conception of cause rising above cause forever higher 
and more remote is not only erroneous but would prove an insuperable obstacle to scientific knowledge. There is then no reason for regarding as misplaced or for otherwise discrediting the chapter which brings forward what is to serve in subsequent argument as an instrument of the most general utility. It is appropriate that a principle of such importance should receive some emphasis in a statement of the general procedure.

\section{V}

Book Beta with its massed questions might be considered to correspond to the guide an author prepares for his own use during the construction of an extensive work, which is not allowed to appear in the work itself except, perhaps, in the guise of a table of contents. It is customary to find in a finished writing that after an introductory statement of the general problem the particular questions are allowed to emerge gradually in the course of the argument. Thus the development seems a more natural one, and it is thought that the interest of the reader is better maintained, than if a great many questions are brought into array before he is at all acquainted with their significance or assured of their relevancy. In Book Beta, however, this latter method is pursued with vigor and not without a conspicuous success. To 
have well put a question is, Aristotle says, the best beginning an argument may have. Only the investigator who has taken a careful preliminary survey of all the difficulties he must encounter, stands in a fair way to know how to proceed, and, in the conduct of the search, to know when he has come upon what is wanted. After this emphasis upon the value of interrogation as a preliminary to affirmation of doctrine, the questions which will arise in the course of the inquiry are rapidly enumerated. Beginning with the second chapter a detailed restatement of the same questions is made, with so nice a balancing of arguments pro and con that the issues appear very genuine. The questions form, as it were, an index of the inquiries which will be pursued in the body of the work.

The principle upon which the questions have been selected is in most cases evident. It seems, for example, entirely natural to ask if philosophy may properly examine not only the "causes and origins" " of being, but in addition the principles of demonstration and the "essential attributes" " of existence. In some of the cases the principle of selection is not so clear as in this

1 aitía kaì á $\rho \chi a i ́$.

2 $\tau \grave{a} \sigma v \mu \beta \varepsilon \beta \eta \kappa 6 \tau \alpha \kappa a \theta$ a $a \dot{\tau} \dot{\text {. }}$ 
instance. It is to be remembered, however, that the atmosphere in which Aristotle taught had its own peculiar vibrancy; certain great questions were the common property of all who essayed philosophic discussion and would be expected to appear in any reflective discourse. The main questions of Book Beta may for the most part be regarded, therefore, as Aristotle's statement of the common issues in the speculation of the day. The minor questions into which the main issues are shown to develop bear the almost unmistakable mark of Aristotelian method. To group about a central problem its subsidiary problems and to subordinate to each of the latter the more specific problems into which it in turn differentiates is a task requiring acuteness and subtle continuity of thought, and performed as it is in Book Beta indicates intensive individual work. Still more characteristically Aristotelian appear the arguments which are advanced on both sides of a given question, as, for instance, in the discussion of the question whether the originative principles are to be considered as universal or individual: if they are universal, they will not strictly speaking be primarily real, for the primarily real is individual; if they are not universal, they will not be subjects for science, since all sciences are of what is universal. 
In composition Beta is one of the most compact and orderly books of the Metaphysics. Its dialectic is for point and brevity unsurpassed ; and although, as a book of interrogation, it makes no endeavor to reach conclusions, it constitutes an effective instrument for the later exposition. The chief difficulties which Aristotle sees before him relate to the unitary character of the "science of first causes" - a question which with its ramifications occupies most of the second chapter; to the admission of other existences than those evident to sense; to the recognition due to genera as explanatory of existence-a problem to which the third chapter is devoted; to the number and permanence of first causes, the degree of their subjection to potentiality; to the utility of the doctrine that "Being" or "Unity" constitutes existence; and, finally, to the validity of a mathematical account of being. The last chapter renews the inquiry into the ultimate reality of universals. These questions and those into which they are shown to lead are so treated that in each case the issue remains in a high degree problematic. Yet there is not in most cases complete reticence as to which of two opposing views recommends itself the more strongly. Sometimes criticism of earlier philosophers enters into the discussion and gives a hint as to the final verdict. Especially 
in the exhibition of what is involved in the acceptance of universals as primarily real, Aristotle anticipatesin indecisive manner, to be sure-his later exposition. It is observable that the problems with few exceptions centre about this great issue; and in this also Book Beta is the keynote of Aristotle's elaborated doctrine.

In an interesting argument, subsequently taken up in detail in the discussion of Pythagorean views, the question is raised whether numbers and bodies, planes and points are primary existences or not. On the one hand the existence of an object appears not to consist in its qualities, movements, relations, so much as in its corporeal substance, body; but body again appears less worthy of being called primary than surface, and surface farther removed from primary existence than line, again the line is subordinate to the point. Body, at any rate, cannot be regarded primary in the degree that surface, line and point, by which body is defined, may be so regarded; since these can exist without body, but body cannot exist without them. Yet on the other hand they are less primary than body, for they are merely limits of the solid, divisions of body.

Another question which bears upon an important subject of Aristotle's thought, is whether it is right to hold that there is a fixed number of originative principles or 
indefinitely many. Again, are such principles all imperishable? The development of the latter question is an admirable instance of Aristotle's fondness for bringing a question to a sharp issue. The poets have sung immortal gods, and in reflective thought also it is usual to distinguish between transitory existence and the permanent. Does such a distinction involve the assumption of transitory principles for explaining transitory existence? If so, why may not the principles themselves pass away? If they are not transitory but are eternal, how will the existence dependent on them differ from the eternal existence-why call it transitory?

It is worthy of notice that the arrangement of questions in Beta corresponds closely with the order in which the main discussion is conducted, and if this is not a further indication of the unity and completeness of the work as a whole, the correspondence is at least somewhat remarkable. If Beta is in fact, as it purports to be, a preliminary gathering of questions, it is at the same time a scheme followed with fidelity by the subsequent argument. 


\section{CHAPTER II}

\section{The Scope of Philosophy}

\section{I}

THE constructive work of the Metaphysics opens, in the first three chapters of Book Gamma, with the determination of the province of philosophy. In determining what is properly subject-matter of what Aristotle has heretofore called the science of primary origins and causes, it is evident that the inquiry must be twofold: what is included in its province; and how, including all it seems to include, philosophy is nevertheless a unitary - science. These two inquiries are necessarily very closely related, inasmuch as the terms upon which a subject is admitted as belonging to philosophy are that it does not disrupt the unity of the science. The fundamental question therefore is, wherein does the unity of philosophy consist-a question aimed at the very claim of philosophy to exist at all.

Philosophy is defined as the science of existence as such. Each special science refers to a particular kind 
of existence and explains the peculiar characteristics of that kind. No one of the special sciences attempts to explain existence as such, what its causes are, and to what laws all existences are subject. It is Philosophy or First Science which deals with existence as such and with the most general causes underlying every existence. Yet one who considers the diversity of existence may well doubt the competence of a single science to grapple with all its multiplicity of forms; and so it is first of all required of the philosopher to show in what sense his is the science of all existences.

II.

Admit even that only the most general causes need be considered, yet these are irreducibly four. ${ }^{1}$ How will a unitary science deal with all of them? When this question was raised in Beta it was suggested that the causes could indeed be different and yet form the subject-matter of a single science, provided their difference consisted in contrariety; since, as Aristotle elsewhere argues, even contrariety implies an underlying sameness, and, as he frequently maintains, the science which considers one of two directly contrary concepts is best fitted to consider the other also, and must, if com-

${ }^{1}$ See supra, page 26. 
plete, take cognizance of both. ${ }^{1}$ But it must be admitted that the four types of cause which have been indicated to be the objects of philosophical inquiry exhibit no such relation of contrariety, and cannot be made to offer this qualification for unified study. Again, it was suggested that if the most general causes could be shown to be always operative in conjunction, that is, if every kind of existence presented indications of the four, there would be at least a presumption in favor of a unitary science. Yet the perplexity cannot be thus dismissed; as a fact there are regions of being in which some of the causes are not operative. Mathematical existence is independent of the cause of motion, which is everywhere present among the objects of natural science; mathematical science has also been condemned-unjustly in Aristotle's view - on the ground that it wholly excludes the final cause. In many regions, however, the presence of all the primary causes is distinctly discernible; if, then, it should appear necessary to have an independent science for each of the general causes, no one subordinate to another, several rival First Sciences would be called upon to explain the existence of so common an object as a house, for instance; one would

${ }^{1}$ Thus, he remarks, the science underlying the curative art gives knowledge pertaining to both health and disease. 
treat of its form, another of its material, a third of its erection, and a fourth of the purpose it subserves. Suppose such a view could be divested of its apparent absurdity, there would remain the difficulty of deciding which of the putatively several sciences might be that crowning, best, most intelligible science described in Book Alpha as the possession of the philosopher. Certainly no one alone could satisfy the requirements.

In exhibiting the justice of the claim which philosophy makes to being a unitary science, Aristotle lays down the general principle that any science will be governed in its selection of material not so much by strict identity of subject-matter as by relevancy to the object of its chief interest. Thus it is at once evident that if the causes were originally determined upon by reason of their fitness for answering the most general questions concerning existence, there is no reason why the unity of the science which develops them need be specifically justified. If it is true of all science that it begins in a mental questioning, it may be said of philosophy in particular that it must produce distinct and final answers to the four most widely applicable questions-what a thing is, of what constituted, by what produced, and to what end. These questions are philosophically exhaustive, and though they are entirely 
distinct and not always even jointly applicable to a given portion of existence, they nevertheless form the basis of a unitary science, and their answers, when accorded the highest degree of universality which a varied world will admit, constitute philosophy.

As the highest science, philosophy demands a certain abstraction from the particular causal series which the various special sciences formulate. This does not mean, however, that philosophy is a summary of less general sciences nor that in its aim at universality it has abandoned distinctive character. The province of philosophy is for Aristotle as well defined, its problem as concrete as that of any science.

In discussing the unity of philosophy, Aristotle is not content to leave undemonstrated the particular interest to which all the philosopher's studies have common reference. It is not sufficient for him to indicate

${ }^{1}$ It may be questioned whether an originally clear insight into the causes would alone have sufficed to make Aristotle's problem thoroughly definite or to give the well wrought unity which the development actually possesses. In fact the discussion of causes is hardly more than an undercurrent in the Metaphysics, although it certainly contributed to mould the form in which the completed work stands. Had not its influence continued to be largely a formal one, there would have appeared more of a tendency toward undue abstractness, against which Aristotle struggled. 
this merely as an interest in the general conditions of being, which indeed it is, but which obviously does not bring to the study such definiteness of aim as the special sciences possess. Now, for Aristotle, philosophy has an entirely definite character, and with that a thorough unity; it is in its way as special as any of what are to-day called special sciences. This unity the Meta physics owes to a continually renewed hold upon the initial analysis of the term existence, as it owes much of its concreteness to the untiring recurrence to change as it is in the actual world.

The inquiry into the unity of philosophy begins, then, with an examination of what constitutes the unity . of other bodies of knowledge. They are formed, it appears, with no such rigid adherence to uniformity of subject-matter as might be expected to be required of what is to constitute a unitary science. There is in every science something primary, some chief subject in relation to which other matters have but a subordinate interest. The science of health, for example, treats of the most diverse objects. The physician must study the indications of health, the means for its preservation or for its restoration; he must be able to distinguish between the body which possesses health and that which does not possess it. The one common element in the 
physician's studies is the reference to health. Similarly, unity may be affirmed of philosophy, since all its studies refer to what may be called primal existence. ${ }^{1}$

\section{III}

The various forms of existence known to experience present well-defined characteristics which enable them to be ranked as primary and secondary for the purposes of philosophical inquiry. Certain of these forms exhibit a sort of self-dependence, as fire, earth, men, the stars, and all things which are referred to as individual objects. Others, as white or warm or three cubits long, cannot be conceived as independently existing. They exist by virtue of the existence of the former; they are attributes, qualities or relations of objects. It may even be questioned whether to be healthy, to be warm, are properly regarded as forms of existence ; certain it is that they do not exist apart from an individual object that is healthy or warm. The selfdependent, then, is primary in existence as it is in thought; in the concept of any of the attributive or relational forms of existence, the primal, substantive existence is implied. And this is recognized in the pre-

1 ovoia. This conception is not fully developed in Book Gamma. The material for the following paragraph appears in the first chapter of Book Zeta. 
eminent position which is accorded to knowledge of primal existence. Aristotle claims that it is, for example, more important to know the nature of man or of fire than to know the attributes or relations presented by these at particular times or under particular circumstances. For philosophy, the relational or adjectival forms of existence have an importance entirely secondary to that of the substantive existence exhibited by those relatively independent beings which act, which grow and decay, which possess color or size or other attributes-which are not themselves attributes of something else.

The distinction in question is represented in speech by the various modes of predication, which Aristotle indicates as "the what" or substance, and quality, quantity, place, time, relation, possession, activity, passivity-although it is much more usual for the list of the categories to occur in an abridged form. It appears that as the other modes acquire significance for thought only by reference to the first mode, so the substantive form of existence is primary, and must be the central-though not of course the sole-object of philosophical inquiry. Varied as are the modes in which we affirm existence, they all imply a reference to primal existence-without which indeed they would not 
be at all ; just as the various subjects of the physician's study could not be what they are, were there no such thing as health. In pointing, then, to what is properly the philosopher's dominant interest, Aristotle accomplishes a two-fold result : he not only dismisses the question regarding the unity of philosophy, but in indicating in what in particular its unity consists he has also chosen the direction in which be must later work. The inquiry vaguely described in Book Alpha as the search for the "cause of things evident" " is from now on presented as a clearly defined problem, viz., the determination of what existence is in its fundamental character. If philosophy is still to be regarded as the formulation of primary causes through the study of existence in its most general conditions, its chief endeavor nevertheless must be directed towards the definition of primal existence.

\section{IV}

Definition is, in Aristotle's view, a characteristic endeavor of philosophy, and serves to distinguish this science from others. It is not the primary concern of any science but philosophy to ask what, essentially, its object is. Other sciences need define their objects only 
so far as is necessary in order not to pass unawares into alien territory. Even the other speculative sciences, mathematics and natural science, enter upon definition no farther than is sufficient for security from this not uncommon error. No science but philosophy is interested in definition primarily. The other sciences do not prove whether the objects of their inquiries exist or not, for it requires precisely the same order of thinking to show that the object is as to show what it is, and what an object essentially is these sciences do not inquire. They accept their objects as evident to sense perception, or construct them through hypotheses, and at once proceed with demonstrations concerning their properties. Definition is of the slightest concern to them.

Just as they assume the existence of the objects of their inquiries, the special sciences also accept uncritically the general principles of scientific procedure. ${ }^{1}$ In all demonstration the point of departure is the axiomatic; no scientist who devotes himself to a limited field undertakes to pass judgment upon the validity of the axioms. The geometrician does not do this, nor does the arithmetician. The physicist has sometimes done so, but under the misapprehension that natural science

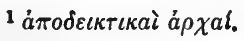


is the science of all existence. The question was raised in Book Beta whether besides inquiring into the "causes and origins" of existence, philosophy is authorized to examine those general principles which constitute the basis of knowledge and are implicit in all reasoning. The answer in Book Gamma runs something as follows: If they are to be subjected to inquiry at all, those truths which give the possibility of certainty and which enable us to say that we have attained knowledge as distinguished from conjecture, must, inasmuch as they are universally applicable in our thinking, be examined by philosophy-unless we are to create confusion by setting up a rival universal science.

There remains another question regarding the province of philosophy. It was asked in Book Beta whether in addition to what are usually designated as existences, philosophy must consider the essential attributes of existence. The very phrase "essential attributes" would dispose a modern thinker to receive whatever it might reasonably denote into a science the province of which was under discussion; and if it were known that such concepts as "contrariety," "identity," "whole" and "part" were those referred to, and the science in question were philosophy, the weight of historic antecedent would be so great as to make 
their admission hardly open to question. But for Aristotle it is not a matter easily taken for granted. There attaches to the term "attribute" the hint of something fortuitous; and even in the case of what are called essential attributes, those which always occur in a given connection, Aristotle shows usually a hesitancy in admitting them to science. The inclusion in philosophy of inquiries regarding the essential attributes of existence is therefore not to be made without a special defence of the propriety of including them. Aristotle's defence involves at the beginning an assertion which is of importance for much of the subsequent discussion, and it terminates in a new argument for the unity of philosophy.

The important assertion is this: that which is said to be can also invariably be said to be one. There is a difference, to be sure, between the concepts being and unity, and we easily and properly distinguish between them ; but in existence whatever is, is onewhat is one, is. The two concepts are companion concepts of equal extension. Accordingly the science which inquires into existence is at the same time the science of unity. As a science it will treat not only of unity in general, but of the various kinds of unity as well; the unity known as identity, for example, and 
that called likeness. As a science, it will also include the consideration of what is opposed to unity; it must be at once the science of the many and the one. It will accordingly examine the various manifestations of the many ; thus it will come to the study of the unequal, the unlike, and all modes of diversity, all that is opposed to the various derivatives of unity. To the study of the one and the many will clearly belong the study of contraries, since the distinction between contraries is reducible in all cases to the distinction between one and many; and contrariety as the unfolding of this distinction is perhaps the most important problem of the suggested science of unity. Aristotle had found the traditional philosophy explaining all existence in terms of contraries. He makes note of this fact and uses it as a new argument for the unity of philosophy, viz., all the contraries proceed from the primary distinction of the many and the one, and are therefore fit subject for a science of unity, which it has been shown is necessarily the same as the science of existence. But this result of Aristotle's argument may be regarded as incidental ; what is of chief significance, is that a reason has been given for receiving the "essential attributes" into the province of philosophy. Those which are specifically named in the summary of the 
argument are opposition, completeness, sameness, difference, priority and subsequence, genus and species, whole and part, being and unity themselves, generally considered; but there are others which might well be added. These concepts, Aristotle maintains, are common to all our thinking and form no part of the province of any special science; these philosophy alone is competent to analyze.

\section{$\mathrm{V}$}

The sense in which philosophy may be said to exercise jurisdiction over the other sciences has now become clear. Along with its central problem regarding existence in its fundamental character, it includes the examination of the axiomatic and the study of concepts. Philosophy alone raises the question how it is possible to arrive at certainty-whether indeed certainty is attainable. It is philosophy which is pre-eminently interested in definition, and it is philosophy which alone attempts an ultimate statement of existence. There are, however, concervable ways in which these claims for supremacy among the sciences might fail. It is, for example, not impossible that definition might be given a place of greater exaltation in the full development of the other speculative sciences, and natural science, together with mathematics, might then replace 
philosophy, or at least dispossess it from the first rank among the speculative sciences, which admittedly are superior to all practical and technical studies. Natural science, however, deals only with objects evident to sense perception; as science, it must treat of causes, but these are, as the science is ordinarily pursued, only proximate causes.

It is possible, however, that natural science might be so extended that it would include in its view all objects of sense, and set forth even their remote causes. As dealing with objects evident to sense-that is, what are called material objects-natural science is nothing more than the science of that which constantly undergoes change. If the mind's grasp were limited to such objects, as certain philosophers affirm, natural science might dispute with philosophy for the title of First Science. But it is generally believed that the world contains existences which by their very nature elude sense perception, but which the mind may nevertheless comprehend or at any rate conceive. Thus mathematics deals for the most part with that which is considered to be devoid of matter. That which is devoid of matter is in Aristotle's view necessarily the unchangmg, and is generally admued that mathematics is occupied with truths that are eternal. It is to be 
observed, however, that with the possible exception of astronomy, for which Aristotle is disposed to retain a place near philosophy, the mathematical sciences are concerned only with what exists abstractly. With existence which is changeless, and yet definite and individual to at least the degree that the beings of earth are individual, mathematics is not competent to deal. The objects of natural science are individual, not abstract, but actually existing; they are, however, but transitory. Aristotle now discloses the reason which has chiefly influenced him to call philosophy unqualifiedly First Science. Besides things natural there are, most men believe, things divine, not evident to sense, though actual, in no way material, changeless; and with these neither mathematics nor natural science can deal. Supremacy may justly be claimed for philosophy, not only since it includes in its scope existence under all its forms and inquires into ultimate causes, but specifically because it is the study of that which crowns existence, changeless being which is not abstract. First Science is, accordingly, "theology." 


\section{CHAPTER III}

\section{The Problem of Philosophy}

\section{I}

WITH the recognition that the inquiry into the principles upon which demonstration depends is properly a philosophical inquiry, it becomes necessary to ask what constitutes the foundation of certitude. It was suggested in Book Beta that if there is to be knowledge as a result of reasoning, the truth of certain principles must be taken for granted. If demonstration must always proceed from something admitted as true, there must exist that which cannot be demonstrated. Its + truth, if there is to be any truth at all, must be acknowledged without attempted recourse to proof ; since infinite regress would otherwise destroy the possibility of knowledge. In Aristotle's view the principle preeminent on account of its universality and its absolute freedom from underlying assumption is the truth that the same thing cannot at the same time and in the same respect both be and not be. All science depends prim- 
arily on the recognition that contraries of any kind cannot at the same time and in the same sense pertain to anything whatever, together with the acceptance of the related truth that if on $\theta$ is to make any statement at all there is strictly no middle ground between acknowledging on the one hand and denying on the other that something is in a given relation with something else. ${ }^{1}$ To the defence of these truths the last five chapters of Gamma-by far the greater portion of the book-are devoted with an ardor which suggests that in intensity of conviction Aristotle may have lost sense of proportion; but the matter at issue is of the highest significance for his entire undertaking. It is the possibility of any certainty, the very existence of knowledge, which is in question.

While there can strictly be no proof of that which is the foundation of proof, its validity is indirectly attested by the fact that even those who attack it are compelled to make use of it in the attempt to deny it. If debate is to arise concerning the most incontestable of truths, it is at least necessary that the words used shall each have a certain definiteness of meaning and not be equally capable of the opposite meaning or of any

${ }^{1}$ For this statement of the principles of contradiction and excluded middle see the Metaphysics 1005b, 19, 20 and 1011b, 23, 24. 
other meanings; otherwise nothing at all is meant and nothing can rightly be understood. And in attaching any meaning, extremely vague though it may be, to a word one utters, one has made use of the principle that what is, is not equally what it is not. To argue that a thing is not alone what it is but also what it is not, is to reduce all things to indiscriminate unity. Now the requisite for any distinction whatever is that what is defined should have a determinate nature, that it should be not wholly indeterminate. Were a thing both itself and anything else whatever, the distinction between the true and the false would at once disappear. Yet even those who make the strange assumption that each thing may be indifferently all, claim that they themselves declare the truth and that the opposed view is false. Moreover in their actions they, like all others, show preferences; and thus they admit in practice the truth of that which they speculatively disavow.

In the fifth chapter of Gamma, Aristotle enters upon a suggestive account of what may have led men to assert that a thing is also what it is not. The chief influence seems to have been a false interpretation of sense perception. Thus if one admit as true the teaching of Protagoras-that what seems true to sense perception is true - since even in the same individual the perception of a 
single object may be subject to great variations, there results a mass of contradictory evidence about any one thing. It is all admitted as equally true, and in the absence of any absolute criterion there has come to be reason for saying that what is, is also what it is not. Or with similar premises one may conclude that no true assertion whatever can be made. Aristotle reports Cratylus to have been drawn to such an extreme in this direction that he disapproved even the master Heraclitus, who first remarked upon the flux of sense perception. In the view of Cratylus even the most meagre assertion is untrue and negation likewise untrue, and all that one may legitimately do is to point the finger at an object, never to go so far as to attempt to name it. Unquestioning acceptance of sense perception as the arbiter of knowledge led in this manner to the denial of the possibility of certain knowledge; at the same time the result need not have been so disastrous, had these thinkers but observed sense perception closely. Aristotle finds that the senses do not give indiscriminate testimony but rather that there is in sense itself some entirely definite factors, which, if they had been carefully noted and properly related, would have afforded valuable criteria.

A less inexcusable mistake was made by those 
thinkers who were perplexed by the fact that out of what seemed the same thing there issued products of lopposite nature. It was somewhat natural to suppose that the original thing was neither one of the two contraries nor the other, but an intermediary somewhat. And so arose the notion that there exists a middle term between contraries. Now there is no doubt that in a sense there are intermediaries between contraries; a favorite example of Aristotle's is that shades of gray are between white and black. The view which Aristotle attacks is that gray, for example, is neither white nor not white. If it is gray it is clearly not white. It is not somehow unintelligibly between white and not white. The empirical fact from which the existence of an intermediary of this nature was argued, was again a fact which, rightly interpreted, would have led to no such confusion. In this case there was failure to discriminate between what the original object is actually and what it is only potentially. At all times it must have definite character of some kind. Its nature can change, it can perhaps assume one of two contrary characters, and it can assume the other in turn; but always one character at a time, for when one exists actually, the other exists only potentially. Aristotle charges both Anaxagoras and Democritus with failure to discriminate 
between the actual and the potential; therefore they constructed systems that were logically weak. The last chapter of Book Gamma returns to the initial statement that those who will not accept the basis of demonstration to be what it is, refute themselves. One who denys that what is, is not at the same time and in the same regard what it is not, will have admitted the truth of the opposing view if he claims that it both is and is not, that all is true. While if he says that it neither is nor is not, that all is false, he will in this have declared his own view false. If in either case, he makes an exception and claims that his own view is true while the opposed view is false, it will avail him nothing; for the only reason he could then give for the exclusive truth of his own view is that it is true because it is true, and so on indefinitely.

As if further to make way for the main investigation, Book Delta sets forth the results of an extended inquiry into important philosophical concepts. It is probable that had there not been the Socratic endeavor at definition, Aristotle might have failed to appreciate the extent to which the presentation of a doctrine is dependent upon a careful account of the concepts which it employs. The terms defined in Book Delta are highly abstract 
and accordingly had acquired a variety of meanings. The meanings must be distinguished, and the distinctions fortified by appropriate examples. Aristotle's success in drawing forth the various significations and showing in many cases how the meanings have developed has made Book Delta one of the most admirable portions of the Metaphysics. Without it the main exposition would have had to make frequent digressions if it were not to give rise to serious misapprehensions. If the Book of Doubts strikes the note of the various discussions, Book Delta gives the key to their meaning and makes them genuinely intelligible.

It is difficult to find the principle which may have guided the arrangement of the material of this book. It appears on the whole that the more important concepts have first received attention, and that towards the close of the book the importance of the terms somewhat diminishes; there seems also to be a certain grouping of terms, one of which has suggested another. Thus "origin," "cause," "element" and "nature" are considered in succession; again, unity, existence and primal existence; after identity, various terms indicative of diversity; prior and subsequent are treated together, and then the potential; quantity, quality and relation form a natural sequence; complete and bound, or limit, 
have an evident connection; several terms indicating kinds of possession are discussed in conjunction with the term denoting privation; "to be out of" is related in one of its meanings to part and whole, which in turn suggest the odd term "mutilated," and also the term genus. The book closes with the analysis of two concepts, the false and the accidental, which are not related to any that precede and which are connected with each other only by the importance they are to have for the book that immediately follows.

+ The importance of the concept of unity both in succeeding discussions and in the general statement of the problem of philosophy makes it not unnatural that a further analysis of this concept should occur at some point in the Metaphysics. This appears in Book Iota. The different meanings of the term One are assorted into two chief classes : the indivisible as regards movement, and the indivisible in thought. To the former class belong what is continuous as to its material, and what is whole in the sense of being a concrete individual. Indivisible in thought is, in one sense, what is universal, in another sense, what is numerically one. Great care is taken to show that unity never exists abstractly ; it is always a definite existence which is one. Remark upon the opposition of plurality to unity leads 
also into a more extended discussion than was given in Book Gamma, concerning the opposed derivatives of unity and plurality. This prepares for the inquiry into the nature of contraries. It is shown that contraries must always have something fundamental in common, else contrariety has no meaning; thus the genus gives the factors of identity, while its most disparate species are strictly contrary to each other.

\section{III}

To have perceived that philosophy is the science of existence as such can hardly be regarded as a distinctive merit of Aristotle's. No doubt he was more keenly aware than others of what such a statement meant. He saw that after its truth had been admitted, any sort of fusion of philosophy with other sciences was rendered forever impossible. Although the implications of the view were probably more clearly seen by Aristotle than by others, the view itself was the common heritage of philosophers. Aristotle's distinctively individual work begins with the perception that in its traditional form the philosophic question is too vague ever to be answered. Observing that the problem of being contains such diverse, unanalyzed factors as to assume without warning any one of many shifting shapes, he sees that until it is properly defined it will never cease to be elusive. 
Until then, hearers cannot be expected rightly to understand, and the investigator can have no steady vision of what it is he is expected to achieve.

It has been said that in every science there is something of central importance, and this for philosophy has been indicated to be primal or substantive existence. Certain phenomena present the appearance of self-dependent existence, while others are plainly derivative or relational and exist in complete dependence on the former. Now while philosophy may find more significance in the existence of an object than in the color possessed by the object, and will leave to other sciences the description and comparison of qualities and activities, it will nevertheless not wholly ignore what constitute universally an important part of existence. Aristotle's chief inquiry is directed towards what is primary in existence. He regards the derivative or relational forms as of only secondary interest for the purposes of philosophy, and holds that their subordination is essential to any clear and effective formulation of the problem. This remains, however, a matter of technique. Aristotle is -not.inclined to take the results of his analysis as indicative of varying degrees of reality. or to erect iwhat philpsophically appears satisfactory into the sole or the most genuine existence. 
Through an early recognition of the diversity of meanings of the word existence and the rigid exclusion of the irrelevant meanings, Aristotle is enabled to make the problem entirely definite, as through the steadfast. subordination of the derivative to the primary senses he is enabled to preserve unity for the science of existence as such-a unity which in no way does violence to the diversity of the facts. It is the function of Book Epsilon to eliminate from the study two senses of the word existence which merely introduce confusion into the science of existence proper. The word "is" often indicates a purely fortuitous connection. Again, it is sometimes used to denote the true; existence is affirmed of what is true, while that which is false is said not to be. Prior to any inquiry as to what is essential in existence, these two meanings have to be definitively dismissed. Not to do so is to confuse the procedure and vitiate the conclusions.

In giving the account of Aristotle's grounds for rejecting from philosophical inquiry existence as the merely true or as the accidental, it is desirable to combine with the argument of Book Epsilon related passages in other books. ${ }^{1}$

' In Book Delta, chapters 7, 29, 30; chapter 10 of Book Theta. 
Truth, in Aristotle's view, requires that such unions or divisions as there are in the real world shall be achieved in thought; that those phenomena which are combined in reality shall also be combined in thought, . and that the mind shall dissociate those phenomena which are dissociated in reality. Now it is not the perception of existence nor the combination or dissociation of phenomena in thought that is of especial significance to the philosopher; rather, it is the existence and the connections and distinctions that are independent of thought and that form its proper object, with which the philosopher is concerned. A man possesses a given quality not because we think he possesses it; his possession of that quality exists quite apart from our thought, and our recognition of it merely stamps our thought as true. Truth is indeed the goal of philosophy, Aristotle has said; and the highest philosophy should give a true representation in thought of existence as it is. Inquiry into the nature of truth belongs, however, to another science; philosophy is concerned with the nature of things, and so need not delay with existence in the sense of the true.

$\mathrm{V}$

The reason for the exclusion of existence as acci- 
dental $^{1}$ is still more urgent. Science, Aristotle has implied, is not only an understanding of events; it must be able to become a discipline. The wise man is not merely one who knows; he is one who is able to teach. But how can one acquaint even himself with the causes of an entirely isolated phenomenon? Much less can he impart knowledge concerning them to another. There can be no science of the purely unique, which by definition the accidental is. Science is superior to the bare acquaintance with particular fact. It has been indicated in Book Alpha that when events of a given kind are described in their essential character, and their causes and origins ascertained, natural law, or the typical and necessary - the true object of science -is disclosed. Of the merely unique no science can be constructed, for there is no opportunity for discovering what is essential in the existence of the unique object. For science it is necessary to recognize the existence of the indeterminate and accidental; beyond that it will confine its attention to the usual course of events. Philosophy, then, as the highest science, can fulfil its purpose only by ignoring that which is irrelevant to its primary object, the general conditions of 
existence. What is characteristic of merely one narrow class of being is accordingly of no concern to philophy; much less what attaches fortuitously to any single member of a class. Complete and normal, and therefore intelligible, events are best fitted to throw light upon the nature of a world in which completeness and order are at any rate the rule.

The entirely unique, then, is inadaptable to purposes of thought; still more clearly, the indeterminate is excluded from systematic knowledge. Nevertheless from a material world the unique and indeterminate will never be withdrawn, nor need it be hoped that knowledge will ever so completely command existence that the intrinsically impossible definition of what is individual will be made.

In view of a possible claim that existence throughout is strictly necessary, Aristotle finds it expedient to develop the concept of the accidental with some care: Besides the examples given in the second chapter of Book Epsilon and in chapter thirty of Book Delta, the third chapter of Epsilon is devoted to showing that all things cannot be necessary, but that there genuinely exists that which is fortuitous, the cause of which is indeterminate. Some phenomena occur in regular sequence and present the character of inevitability ; other phenomena follow 
for the most part a regular sequence but admit of exceptions, and this implies that there are phenomena which are anomalous and which are exceptions by their very nature. Experience shows that a given set of antecedents is usually followed by determinate consequences, and we say that the former are the causes of the latter. But it not infrequently happens that a given cause does not have the result which we should expect. Other causes interfering in not only an unforeseen but in a strictly indeterminate manner may negate or otherwise modify its operation. Aristotle's example is something as follows: When a man sets out for Miletus after having made all due preparations for the voyage, there is good reason for expecting that after a proper lapse of time he will arive at Miletus. Driven by contrary winds, however, or captured by pirates, he may perchance find himself at Egina instead. The event is called popularly a mischance, and in truth it is due in part to chance, for besides the definable causes which operated, there was undeniably also an indeterminate cause. The experienced husbandman in sowing his grain may fairly expect the seed to germinate and pass through the usual stages to maturity. Drought or flood may thwart his expectations. The science which has for its object the growing of grain will con- 
cern itself with the normal course ; it will take account of the interference of indeterminate forces only so far as to recognize their possible appearance. ${ }^{1}$ The building of a house may lead to numerous and diverse events which could not have been foreseen when the construction of the house was undertaken. To some it will be a pleasure, to others it may bring evils .untold, but of these the architect cannot be said to be the cause. Rather, they are due to chance. When the house has been completed and offers shelter to whomsoever may abide in it, the purpose of its construction has been accomplished and the art of architecture is absolved from responsibility for what further may take place within the house. ${ }^{2}$ Any train of events is likely to end in an event whose nature cannot be said to be determined by ascertainable antecedents ; any cause or series of causes has in it something not previously determined. And this Aristotle gives as the reason why variety persists in the world. Otherwise the world would have contained at the beginning all that could ever appear ir it- there could be nothing new. ${ }^{3}$

It is evident that in excluding the accidental from the

${ }^{1}$ Cf. Physics, 198b, 20.

'See 1026b, 6-10.

${ }^{3}$ Cf. 1027a, 29 et seq. 
inquiry, Aristotle is not disposed to discredit the fact of its existence; rather, he emphatically asserts that its existence must be recognized. Because its nature is what it is, it cannot be subjected to investigation. Formulated knowledge of any kind must be directed towards that which, if not universal, is at least usual, and must disclose what is significant about the object of its inquiries. Otherwise it repudiates its claim to be scientific. Any science deals only with the facts that are relevant to the essential purpose of that science. A science, for example, which should treat of the craft of carpentry, of the qualities which the men who pursue that craft must possess, would ignore qualities which such men possess by exception or which though generally possessed have no relation to the carpenter's craft as such. A carpenter may possibly be able to prescribe for disease. This Aristotle would call accidental; it does not spring from his capacity as carpenter. Carpenters usually may be blondes; this too is in a sense accidental and out of relation to the craft. It may occur that a cook seeking only to please the palate hits upon a concoction which proves to be of remedial virtue; this, Aristotle says, is accidental, for it is not the purpose of the culinary art to cure. It is evident that a science that does not ignore the accidental and 
irrelevant aspects of its objects will almost necessarily lead to error. Such a science would for instance be found guilty of asserting that it is the cook or the carpenter who effects cures, not the physician. Indeed such a method of thinking might be employed to prove that cook and carpenter are one, and is, Aristotle has suggested in a historical connection, a fruitful source of sophistry.

It seems that the conclusions of Book Epsilon have accomplished not only a negative but a positive result as well. The senses of the term existence which are unfit for philosophical inquiry have been dismissed; and further, in the endeavor to show that the accidental genuinely exists there is an important forecasting of conclusions to appear in the main development. 


\section{CHAPTER IV}

\section{Primal Existence}

I

Substantive or primal existence has been selected as the central object of philosophical interest; ${ }^{1}$ and the

'See supra, pages 44, 45. ovoía or "the what" is, Aristotle says, clearly primal to all the other modes in which existence is affirmed. Cf. 1003b, 5-18; 1028a, 13-20; 1045b, 27-31; 1069a, 1921. In whaterer way one considers it, the substantive is primary: primary in concept, since in the concept of any of the other categories is implied the concept of the substantive; primary for knowledge, for never do we know anything completely when we know only its quality, its quantity or where it is; we know it when we know what it is; primary in time, since none of that existence which is expressed through the other categories exists separately and independently, but is relational, derivative, while the substantive alone is independent. $C f .1028 \mathrm{a}, 31-\mathrm{b}, 2$. Now, since in Aristotle's view the primary is particularly fit to be scientifically investigated, his conclusion is that the question "asked in ages gone and asked to-day, always asked and always puzzling," what is being? must for scientific purposes be resolved into the question: what is primal existence? 
problem is briefly: What constitutes primal existence? Aristotle demands that its solution be a real one; no mere dialectical disguising of the question will suffice. And its solution must also be one that is intelligible in the light of this world; here are plants, animals, stars and men-it is these and such as these that have been called primal existence: what constitutes their being? It is not to be understood that the search is to be confined merely to that which is sensibly perceived-in fact it cannot be thus restricted-but here at any rate it must begin.

With characteristic directness Aristotle makes in the second chapter of Book Zeta a brief enumeration of what are generally recognized as independent existences, and further of what possibly should be so regarded. Such objects as animals, plants and inanimate natural bodies, as well as their component parts, present prima facie evidence of self-dependent existence. Some indeed believe that nothing exists beyond that which is perceptible to the senses. First reflection, at any rate, inclines one to attribute primal existence exclusively to the corporeal. That the objects of sense, however, are independent and primal either solely or chiefly is not a foregone conclusion. Further analysis may indeed lead to the inquiry whether primary existence is presented at all in the corporeal. 
Many of the most important questions in Book Beta started from the division of opinion among philosophers as to what is most deservedly called primary in existence. Some have held that unity and point, line and surface, by which bodies are bounded and defined, are existences more fundamental than the corporeal, and in their nature prior to it. It has sometimes been maintained that the forms of primal existence beyond the realm of sense are necessarily of a far higher order, since they are changeless and eternal. Such existence Plato affirmed both of the Ideas and of mathematical entities. It is further observed that existences of this nature have at times been held to be various ; Speusippus, for example, sought to establish independent principles for numbers, for magnitudes and for soul. In contrast to this view Aristotle refers to others, obviously the Pythagoreans, ${ }^{1}$ who identify the Ideas with number and derive therefrom all other existence, including magnitudes and whatever is sensibly perceived, even the heavenly sphere. In subsequent discussions Aristotle subjects these views to careful inquiry in order to ascertain in how far they are tenable; if there is primal existence remote from the corporeal and independent of it, it is necessary to inquire why it is said to

${ }^{1} C f .985 \mathrm{~b}, 23$; 986b, 8; 989b, 29 ; 990a, 32, et passim. 
exist and of what nature it is. Such an inquiry, however, presupposes a clear understanding of what is meant by primal existence:in other words it presupposes the completion of that which Aristotle regards as the most difficult philosophical inquiry. Nearly the whole of Book Zeta is required to attain a definition of primal existence.

A preliminary definition of primal existence has been given as that form of existence to which other forms are attributed and which itself is not attributed to any underlying or more fundamental existence. ${ }^{1}$ It is first to be observed, however, that as the word existence was seen to have several meanings, so the term for primal or fundamental existence is used variously. In Book Delta it is shown that when we speak of what a thing is essentially or fundamentally, as distinguished from what happens to it or what accidentally attaches to it, the meaning which we convey is by no means unequivocal. What a thing is, regarded as a concrete totality, is a possible meaning. Sometimes, however, reference is made only to what is tangible in the object-the object as it can be said to occupy space and to have weight. It comes about then that in a more general way one may say that a thing is fundamentally that of 
which it is made. According to the preliminary definition primal existence can readily appear to be matter. ${ }^{1}$ It may seern on the other hand that an object is essentially that which a definition applicable to it will bring out by means of naming the genus, species and subspecies. Or if the less general traits of the object are regarded as of slight importance, what the object is fundamentally may be supposed to be indicated by referer ce to the class of objects to which it belongs. If then this is a frequent practice there will appear a tendency to merge the class with that which includes it, with the result that what is essential in the objects of ordinary experience will appear to be that which is most nearly universal, perhaps even Being or Unity.

I The need for a more profound study of the conception of primal existence becomes evident when it is seen that the preliminary definition admits at the one extreme matter as the essential constitution of the objects of experience, or at the other extreme allows that, passing farther and farther from what an object is in its concrete totality, one finally arrive at the highest universals as embodying all that is fundamental in exist-. fence. Aristotle's own judgment as to which of the meanings considered is philosophically acceptable, is 
rendered only after an extended study of the empirical fact of It appears to him possible, however, to rule oumed advance certain of the meanings which appear in common usage and about which systems of reflective thought have been erected. They can be shown to be inappropriate to any statement whatever of primal existence. Yet it was not unnatural that in the development of philosophy these conceptions should for a time have appeared satisfactory, as the following. paragraph will endeavor to show.

\section{II}

The preëminent empirical fact is that of change. Change appears on all sides in the world in which we find ourselves. In change our questions have their origin; in the situation of change they must discover their solution. Very early in the history of thought it became evident that if there is to be change, there must also be that which abides-else change has no meaning. That which abides was accordingly seized upon as the chief object of reflective inquiry, and was identified with what has been called primal existence-" that which remains the same while undergoing change as to its modifications." 1 The conception of the abiding 
tended, however, to push farther and farther from that which has definite character until the ention of matter utterly devoid of quality appeared ne the logical outcome. Let one in thought remove from a body all its attributes and relations-its functions and potentialities, the modifications wrought in it during the course of its existence, its length and width and depth -and what remains but the matter? Yet matter is, as the process by which its conception is reached demands, something wholly unknown and indefinalole. ${ }^{1}$ It is not an individual object nor can it be described as quantitative, qualitative, nor as possessing any of the characteristics by which existence is determined. Individual character, definiteness, and whatever renders existence intelligible it completely lacks. Such a result puts a quietus upon the endeavor towards knowledge, for this all pervading, characterless substrate is quite incapable of intelligible description.

Nor indeed does the conception of matter at all adequately account for the facts whence it developed. If there must be something which abides in change, nevertheless there is the change still to be accounted for. And were it assumed that there is resident in matter a force which somehow issues in the changes we ${ }^{1}$ Cf. 1036a, 8; 1037a, 27. 
observe, ${ }^{1}$ it remains that these processes are themselves greatly diversified and that they possess for the most part well differentiated characters. Finally, were it possible to ignore change altogether, as being perhaps a kind of illusion, and to consider the world as it would appear were all the changes this instant arrested, there would still remain what could not be expressed in terms of mere matter. Even in a static world there would be differences between objects, there would be distinct characters, there would be types. It is difficult to see in what way attributes and relations of any kind could be affirmed of an entirely characterless substrate. Yet it is only in dependence upon primal existence that the attribute or relation can be said to exist at all. Aristotle's conclusion is that matter cannot be the primal existence toward which philosophical inquiry is directed.

III

Turning in a new direction to a meaning which in contrast to that first tested promises to bring the inquiry to the clearly intelligible, one may ask if the universal does not preëminently, represent what is fundamental in existence. When one considers the vast possibilities of classification, when he observes that not only do

${ }^{1} C_{f} .1071 \mathrm{~b}, 30$. 
objects fall into significant groupings of like with like, but that changes as well are of perfectly distinct types and that they may almost invariably be observed to obey orderly sequences, it may well occur to him to ask if primal existence is not the type, the kind. This is a view which important philosophers have held and it is one which recommends itself because of its promise of the most complete intelligibility. The typical, however, is essentially the permanent; that is what the word signifies. Through a multiplicity of individuals the type is one; individuals arise and perish but the type remains. So conceived the typical appears to be nothing dynamic whatever; assuredly it is not the agency for initiating change. Yet change is the significant fact about these objects of ordinary experience the existence of which philosophy seeks to define. If the type is what is fundamental in existence what claim upon reality has this particular horse, or this particular man? In short, why are there individuals at all? And what sort of relation do they sustain to their respective types?

The recognition of the typical is without question a notable advance over explanation by reference to a homogeneous material substrate. Each method has a certain claim to consideration, for each grasps at an 
important aspect of the empirical fact. But as the first proved a defective method, the second also shows deficiencies which are the more conspicuous because of the popularity the method has had. It has been adopted enthusiastically by those who were eager to arrive at transparent statement, by those whose training has been predominantly logical, and by those who wish to see in the world an orderly arrangement pleasing to the reason as is a well trimmed landscape to the eye. Primal existence, it must however be remembered, is that which exists independently, not by virtue of some underlying existence. The universal, however, exists only by virtue of existences that are concrete and individual. ${ }^{1}$ Individuality is for Aristotle's thought the very kernel of existence. ${ }^{2}$ The genus does not exist apart from its species, and these in turn do not exist apart from the last possible differentiæ. The individuals must accordingly be the existence underlying the genus and the various sub-classes. Apart from -individuals the type has no intelligible existence, and for the doctrine of types the existence of individualswith all their changes-remains an unconquered fact.

${ }^{1}$ Cf. 1038b, 15, 16.

'1003a, 9; 1029a, 28; 1037b, 27; et passim. 


\section{IV}

Another solution is suggested. Is it not possible that the real existence of any of the beings that have been selected for inquiry is indeed not the type but something not wholly remote from the type, namely the traits it possesses in common with other objects of its class together with the characteristics peculiarly its own -what may be called its intelligible constitution ? ${ }^{1}$ Aristotle examines in the fourth chapter of Book Zeta, the value of definitions for adequately expressing what is thus fundamental in the objects to which they apply. The discussion is quite naturally from a logical standpoint. The definition is to be regarded as the concept of that in which consists the intelligible identity of the object to which it applies. ${ }^{2}$ It is evident that a concrete object may be shorn of many of its attributes without loss of identity. The definition properly makes note of only those indispensable characteristics without which the object to which it applies could not be recognized as the same object. A definition which would apply to the man Socrates, for example, would not state that he is cultured; for culture is merely something he has acquired, and were he to be deprived

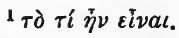

$$
\begin{aligned}
& { }^{2} C f .1017 \mathrm{~b}, 22 .
\end{aligned}
$$


of it, he would none the less be Socrates. If it is true that whatever definite character there is in an object, which we cannot in thought remove from it without destroying the identity of the object, contains all the es-sential factors of the existence of that object, it follows that objects in their fundamental existence are adequately represented by the definition.

Before considering the finality of this proposed statement of primal existence, it is desirable to take account of a certain advantage such a view has. It will offer in what may be called the integrity of the concept an excellent test of what should be considered independent existence; definition, strictly speaking, will be found to apply only to what can exist by itself. ${ }^{1}$ The same distinction which logic makes between so-called independent or integral concepts and the concepts which are derived from these and which as definitions are never final, may be found to hold between that existence which is independent of other existence and hence primal, and that existence which depends upon the

- former. Examination of concepts reveals that the factors which enter into the composition of some make up a complete unity and are not, as in certain other con-) cepts, loosely interrelated. The former constitute true

${ }^{1}$ Cf. 1030a, 1-17. 
definitions, no element of which bears a resemblance to the total concept. ${ }^{1}$ An example is the concept of the sphere; we define the sphere as the solid figure the points on whose surface are equidistant from the center ; the completed concept bears no resemblance to any of the factors which enter into the concept. In concepts which have not such close unity there appear elements that are similar to the completed concept; thus the concept of white man is formed by adding to the simple concept of man the characteristic of white. Such a concept either involves a certain repetition of that which it assumes to define; or if it clearly exhibits both factors in all desired completeness, it cannot bring them into any close union, since neither demands the other, whiteness being easily conceivable apart from man, and the concept of man complete without whiteness. As reason will not rest with the loosely composite concept but must reduce it to concepts which possess an organic unity before it may claim to have achieved definitions of permanent worth, so the question of what is fundamental in the existence of an object will obviously not be given a valid answer if traits that are sometimes present and sometimes not are indiscriminately included with what is indispensable to the identity of the object.

$$
{ }^{1} C f \text {. 1031a, } 5 .
$$


Fundamental existence will not be indicated by loosely composite concepts but by concepts whose parts make up a unity. White surface is not an instance of primal existence, though surface may be so regarded. White man does not denote the fundamental existence of him who is a man.

It may possibly be argued that if the concepts white man, white surface, cannot because of their tendency to inner disruption be admitted as indicating anything primal, the concept of whiteness is a well-wrought unity and may therefore be taken as an index of primal existence with as much justice as the concept of man is regarded as indicating what exists independently. Aristotle admits that in a sense definition can truly be made of such existence as whiteness $;^{1}$ in other words, the concept of whiteness is integral. Logic may nevertheless distinguish between simple concepts which are primary and other simple concepts which depend in a way upon the former. Thus whiteness cannot be defined without some kind of reference to objects which are white. Primarily the definition applies to forms of existence which are self-dependent. It may apply to the other forms as well, but only secondarily and by recognition of the independent integral concept. ${ }^{2}$

${ }^{1} 1030 \mathrm{a}, 20-32$.

${ }^{2}$ 1031a, 1-14. 
Dependent concepts are not necessarily of so manifestly dependent a nature as is the concept whiteness, which has been taken as an example. In cases where an attribute attaches to only a single class of objects, the attribute is in speech not uncommonly allowed to represent the object, and the concept of the attribute possessed by the objects of the class may not readily reveal its dependence upon the concept of the objects themselves. Examples are the concepts of the odd and the even. It is only number which is odd or even. Accordingly one may speak of the odd, meaning of course odd number; as it is only number which can be odd, explicit mention of number drops out. In defining the odd, then, there is much less probability that the dependence of the concept will be invariably recognized than in the case of attributes like white, which occur in such diverse connections that they never come to represent a particular class of objects. In speech, Aristotle observes, odd is freely substituted for odd number, while white alone does not suffice to indicate an object which is white ; in thought, however, the concept of odd is as genuinely dependent as is that of white. The dependent or composite concept, as the analysis has shown, is indicative of what exists dependently; the independent integral concept, however, may be considered at least an index of primal existence. 
With so much to be said in favor of the definitionthat is, the concept of what constitutes the intelligible identity of the object to which the definition appliesas giving what is fundamental in the existence of the object, it becomes necessary to distinguish between two possible interpretations of the importance to be attached to the definition, for exhibiting primal existence. The expression which Aristotle has used in the inquiry into the nature of concepts has invariably been that the de. finition is of primal existence, not that it constitutes

such existence. ${ }^{1}$

The question may then arise whether that which conveys the identity of an object and which corresponds to the simple concept is the same with the object or whether it exists independently of the object - possibly entirely apart from it. Some philosophers have maintained that the Idea, or form of an object exists quite removed from the object. ${ }^{2}$ The question is not to be confused with the question as to whether the intelligible character of an object is equivalent to the totality of traits the object at any one time is said to possess. It will readily be admitted that what is

1031a, 2 et passim.

${ }^{2}$ In the separate existence attributed to definitions Aristotle finds one origin for the doctrine of Ideas. $C f .1078 \mathrm{~b}, 31$. 
fundamental in an object-that which conveys its identity-is not the same with the object possessed of all the attributes which may chance to attach to it. Socrates in his fundamental character is not to be considered totally identical with Socrates as he is known. Yet in the sense in which the question is raised, Aristotle holds that the object is the same with its fundamental character. ${ }^{1}$ Socrates as he is known presents many characteristics which are accidental, which are merely incidental to his identity. Were he deprived of these, he would still be in an important sense the same Socrates; but were the essential factors of his identity withdrawn from his existence, it is almost truistic to say he would no longer exist. What is fundamental in the character of an object, its intelligible existence-resides in the object, and is in the truest sense the same with the object.

If it were to be assumed that what is fundamental in an object exists outside of it-in the form of an Idea or otherwise-it would be necessary to inquire what relation such an entity might bear to the object whose nature it is supposed to determine. It would further be necessary to inquire how far such an entity could be intelligible. Certain philosophers have indeed asserted

${ }^{1}$ The defense of this view occupies Chapter 6 of Book Zeta. 
that the object "participates" in these supposed supernal entities. What this means Aristotle finds it impossible to say, nor does he find any other relation more evident. If it be said that objects are intelligible by virtue of some such entity-and, as has been indicated, it is in terms of the fundamental nature of an object that it is truly intelligible-in what way are the supernal entities themselves intelligible? Unless other explanation were devised, there would have to be assumed a still higher entity expressing the essential nature of these; the same process would require a yet higher entity, and so on indefinitely. ${ }^{1}$ If what is fundamental in man exists not in man but in some way beyond him, how can there be knowledge of what man is, since admittedly knowledge attains its goal only when it discloses what is fundamental in the object known? Clearly, it would be necessary to attain knowledge of Man supernal. Such an entity might exist, but it would be beyond our ken. The conclusion is that if an absolute separation is made between that which exists and that which is known, the latter cannot exist and the former cannot be known. 


\section{CHAPTER V}

\section{Primal Existence (Concluded)}

WITH the decision that it is not reasonable to suppose that the fundamental character of an object resides elsewhere than in its own existence, Aristotle undertakes in the seventh chapter of Book Zeta a direct study of change, which from the standpoint of philosophical inquiry is the empirical fact of the highest significance. This study might have been begun earlier had it not been desirable at the outset to take measure of existing doctrines.

One may reasonably hope that in tracing the conditions under which new objects are formed, and existing ones act, suffer alteration or perish, it may be possible to disclose what is fundamental in their existence. In such a study one may hope to determine what importance the intelligible identity of an object has for the statement of its existence, and what if aught else is essential. 
There are in Aristotle's classification two great divisions of change: on the one hand that absolute change involved in generation-decay, creation-destruction; on the other, relative change, as in qualitative alterations, local movement or variations in size. To avoid an undiscriminating survey, Aristotle concentrates his initial effort upon one kind of change and only later considers how the theory must be altered, if at all, in order to include the other kind also. ${ }^{1}$ The selection of the so-called absolute change as the chief subject for study rests probably upon the hope that at the point where beings arise or where they perish will most readily appear what essentially they are. It is natural to suppose that could one but know the conditions under which things come into existence or pass out of existence, one would hold the secret of their being. Could one but intelligently witness these critical moments, one might expect to find what constitutes the existence of the objects themselves. At no other point in their careers is change so significant. The intermediate and lesser changes have their meaning; they assist toward a knowledge of the specific character of the object. They may indeed obscurely indicate what fundamentally the object is; they may be found to dis- 
close a truth identical with' that of the great change. But primarily, luminously, the truth is given by the change that has been called absolute. To what degree the basis of Aristotle's choice was consciously laid, it is impossible to say. The conspicuous use of production in the absolute sense and the subordinate place given relative change could, however, have been authorized by no other reason than the greater fruitfulness of the concept of absolute change and its superior adaptability to presentation.

Concrete objects of our experience manifest for the most part the characteristic of having been produced. ${ }^{1}$ Some of these objects have been produced through the reproductive force of nature, others through art; yet others have arisen in an anomalous and indeterminate fashion-spontaneously, ${ }^{2}$ it may be said. Genesis, in the sense of the appearance of a being which did not before exist-as distinguished from change in a being already existing-Aristotle accordingly observes to be of three kinds: generation in nature, artificial creation - as in works of man's art-and spontaneous origination. By the latter Aristotle would indicate geneses that have no assignable cause - origins whose sole ${ }^{1} C f .1069 \mathrm{a}, 30,31$.

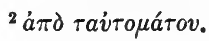


sponsor is chance. He does not mean that they indeed have a determinable cause could one but search it out. They have not merely an unfathomed cause but one by its very nature unfathomable. ${ }^{1}$ Therefore this kind of origin is of no avail for the purpose in hand. Fortunately, moreover, it is the atypical, the abnormal, by its very concept; and hence its utter lack of determinable character does not affect the success of the investigation as a whole. The vast majority of productions have strictly definite antecedents, and easily lend themselves to analysis.

Aristotle considers first such geneses as occur through man's art. Here, for example, is a bronze ring, the result of man's handiwork. Before its maker's thought, skill, strength, had operated, the bronze ring did not exist. Bronze existed, and in another sense ring also existed; it was not fashioned by the man. But he made the ring of bronze. He took a shapeless material and he gave it a chosen shape. He did not therewith make the shape de novo; he copied the shape of another object-one in nature, perhaps-or embodied a form represented in the mind. Neither did he make the bronze which he used. The bronze was made, to be

${ }^{1}$ See supra, p. 67. 
sure, but by the smelter's art, which in turn wrought upon more primitive materials, made the bronze of something, made it to be something it was not beforeas the bronze ring also was made. A different example may be offered: the physician cures, he produces health. It is indeed an intangible product, yet the production is no less genuine, for without the physician's intervention the patient is not restored to health, and the outcome is entirely different. But does the physician make health? In a sense he does; for he knows the bodily conditions indispensable to health and these he establishes by all the means he can command. But in another sense he does not make health - for health exists where the physician has never exercised his art, and it is by close observation of health as it exists naturally, by keeping before his mind the ideal of health, that the physician is able to produce it artificially. ${ }^{1}$ And note again, as in the case of the artisan in bronze, the physician must work upon a given material. He must take the patient as he finds him and, using such medicinal means as are appropriate, establish the natural processes in the right courses. As the worker in metals makes a perfect 
bronze ring by a steady vision of the form to be given to the bronze and a clever manipulation of the material, so the physician succeeds by steadfast adherence to the ideal of health and by judicious appliance of means. The results are a ring fashioned of bronze, health embodied in a human being - not of course a merely ideal ring nor disembodied health. It is true that despite the best craft, either effort may fail. There may be a flaw in the metal and the ring may break; there may be conditions beyond a physician's control, and the patient may die. In all efforts of man's art it is evident that two factors are involved, the material and the form which is to be given to it; and every result of man's art is matter and form in one-shaped, wrought material.

But the material when it comes to man's hand is by no means absolutely formless, it is not entirely devoid of character; it is only relatively so-that is, with reference to the purpose it is now to fulfil. Form of some kind every material already possesses; it is merely that new form is to be added unto it. ${ }^{1}$ The evident reason for Aristotle's insistence on this point is that all materials which man's constructive or perfecting art employs

${ }^{1} C f .1049 \mathrm{a}, 17-20$. 
are definitely describable, as of such and such kinds. Moreover were men at work on a characterless matteras one devoid of all form would be-there would be no necessity as there now is for the careful weighing of the advantages for prescribed ends of certain materials over others; there would be no differentiation whatever as to adaptability to various results. ${ }^{1} \lambda$ Strictly, from the standpoint of man's activity, no unformed matter exists, and, excluding the mental representation of a form, ${ }^{2}$ there is no pure form. Health exists in bodies, shapes exist in bronze and wood and stone, or something else material.

It is also evident that the objects of man's art are in all cases individual and definite ${ }^{3}$-a particular house is made of particular stones or timbers and by particular workmen. Anyone knows in a general way what a house should be, and also in a general way what material will be used in its construction, and that its construction will take place through certain agencies. But when a house is built, it is a particular house, made of particular materials-in other words, it is a concrete, individual object of a specific

${ }^{1}$ Cf. 1044a, 28, 29.

${ }^{2} 1032 \mathrm{~b}, 1$ et passim.

${ }^{3}$ Note the frequent expression $\tau \delta \delta \varepsilon \tau \iota$. 
kind. Its plan may be identical with that of many other houses the architect has built; nevertheless, it is individual, because the plan is here developed in a portion of material that is identical with no other portion of material in the world. ${ }^{1}$

In the case of beings that have a natural origin, the analysis of the factors involved, and the results attained, follow much the same lines as in the case of things produced artificially. We may take the example of ten trees in a row which look so much alike that we say we cannot tell them apart. Yet we do tell them apart, for we count them; and were the form of one in every respect absolutely the same as that of the others, nevertheless the trees would be distinct, and we would never suppose that one tree contained the material of the other trees. Nor, however alike they may be, would we suppose that they were all sprung from one and the same germ. Each had a particular origination, as each is now an individual tree, developed from separate matter, after a common manner. Objects in nature are not, however, for the most part of the striking identity in every detail of appearance which the example improvised has assumed. Aristotle in-

${ }^{1} C f .1049 \mathrm{a}, 24 ; 1070,31$, 
variably makes provision for idiosyncrasies, variations from the type, but he does not regard them as of primary importance for the inquiry now under way.

The striking feature about natural geneses is the obe-

1 dience to type. The animate forms known to Aristotle as a naturalist exhibited remarkable groupings, and each group appeared to have a law unto itself which the individuals, with minor and perhaps explicable exceptions, observed. Others had noted the same fact and had been dazzled by it-at least so Aristotle reports-to the extent that to them the type had come to seem the common parent. But to Aristotle such a notion appeared unnecessary, not to say futile and fundamentally unintelligible. ${ }^{1}$ Discarding the genusand $a$ fortiori the higher universals-as in no way helpful to the explanation of natural origins, he sees here again only a process from concrete individual to concrete individual. A tree appears; it springs from a particular seed; the seed was borne by a particular tree of prior existence; this earlier tree in turn arose from a seed. To this explanation nothing need be added except that the tree is matter and form combined; the materials of its nutrition it works up in a characteristic

${ }^{1}$ See infra, pp. 164, 165. 
manner and it is not only a tree, but a definite kind of tree. The manner of nutrition, we may say, is ancestral, it is inherited from the parent tree; but yet it is now this tree's own which it will in turn transmit. It was conveyed to it in the germ; it was not derived in imitation of some ideal and perfect tree, by participation in the type Tree. The tree's growth proceeds in definite ways because the tree is a live thing; it has specific activities and is capable of disposing its material after predetermined lines. It too is definite, individual; it is matter and form combined-particular matter and specific form.

Passing onward throughout the reach of natural geneses, the analysis is unaltered, the result remains the same. Everywhere it is the individual which is real; the individual everywhere is matter and form combined, and the descent has always been from that which was itself individual; itself composed of matter and form. ${ }^{1}$

In gathering up the results of this study of change, too much emphasis can hardly be placed on the observation that whatever is produced in nature or art pos- 
|| sesses a distinctive character of its own; it is formed out of something as material; and it is brought into being by something which may be called the agent or efficient cause. ${ }^{1}$ Those things which arise through the reproductive force of nature are such as man or animal or plant; and that out of which they are produced is, generally stated, matter. What is produced by art is likewise made from matter. Objects of either class may or may not exist; and this is the token of their material nature. ${ }^{2}$ It can be further observed that in general that which is produced possesses a character which resembles the character of that by which it is produced; it may be said that the form of that which is produced is similar to the form of that which produces. This is especially clear in the case of plants and animals. It may not seem so clear, Aristotle admits, in the case of things that are wrought by man's art or power or thought; and indeed some of the works of man seem automatic, ruled by chance, just as do some of the works of nature. Nevertheless the typical objects of man's creative activity arise from a form which dwells in the mind. Thus, so far as its form is

${ }^{1}$ Cf. 1032a, 13, 14.

${ }^{2} 1032 \mathrm{a}, 20-22$. 
concerned, a house is produeed from the plan of a house in the architect's mind, a statue from the artist's conception. Here, as in the case of natural production, it may be said that like springs from like. ${ }^{1}$

It is well to foresee that the objection may arise that the works of man are the mere result of what he does, that they spring from his acts rather than from his thought-from the form in his mind. If the course which leads up to the creation of a completed work be examined, the process is found to be something like this: In the first place a desired end is represented; that this end may be brought to pass, it is necessary that certain conditions should be established; these conditions require the preëxistence of certain other conditions. Thus tracing backward a chain of circumstances, the mind discovers one set that is within man's control. Acting upon these conditions enables one to bring to pass the desired end. ${ }^{2}$ And in this sense it is surely admissible to say that the end arises from its representation in thought.

But a further objection may be raised that, since every act of producing presupposes material, the pro-

${ }^{1} C f .1032 \mathrm{~b}, 11-14 ; 1034 a, 33-\mathrm{b}, 1$.

${ }^{2} C f .1032 b, 6-10$. 
cess by which man produces may be from the material to the completed object instead of from the idea to the object. This raises the question: Is matter ever an essential part of the concept of the completed object? An affirmative answer appears to be demanded in the case of such an object as a bronze ring; the concept includes reference to both the form and the material. There are very many cases in which things are named in accordance with the material of which they are made, a wooden image, a stone house. In other cases, however, the product of human activity is not conceived in such a way as to suggest the material or conditions from which it proceeds. In the example which Aristotle chooses, the man who has been brought to health by a physician is not called a well sick-man; and the reason suggested is that the subject in which changes have been wrought, namely man, has remained a constant factor through the change. There is nevertheless even in such cases as this something which may rightly be regarded as material, which has not altered itself but which has been altered by reason of the form in the mind. The physician has found certain of the bodily processes abnormal; by effective means he has directed them in accord with the ideal of health, until with the readjustment of functions health has been established. 
It is clear that the result would not have been accomplished except for the physician's knowledge of what constitutes health; the disordered processes could not of themselves have wrought the cure. Nor can it be said in cases where the material is more evident that that which in itself possesses no distinct form, as the wood and stone from which a house is made, is the origin of the form of the actual house. Its form is the idea of the architect which has been embodied in wood and stone.

The aim of this argument is to establish the claim which the form or the intelligible identity has to a place in the definition of what the existence of any product of man's activity fundamentally is. Aristotle maintains that it is impossible to regard the form either as the mere result of actions or as an epiphenomenon of the material. But the study of the conditions under which objects are produced cannot have progressed to this point without disclosing that the material of which an object is made is indispensable to the existence of the object. If the form does in its own right enter into the fundamental constitution of an object, it is nevertheless not all that is essential. $>$ In the statement of what the existence of an object is fundamentally, there is equal necessity that recognition be given 
the material. It is impossible to hold that the material is after all unessential and should rather be regarded as an element of the same nature as those which may enter into a description of the object, but which are not indispensable to its continued existence. It is equally impossible to hold that what is called material is by proper analysis a part of the form; and that the form thus understood expresses the whole of the object's essential existence. The result of the empirical study was to show that even if a form may be realized in various materials, and one material somewhat indifferently substituted for another, nevertheless, if it is to be realized at all-that is, if an object is to exist-some material is indispensable.

The distinction between material and form is especially conspicuous in the products of human activity; the versatility with which a material is adapted to diverse forms, the wide possibilities of realizing a single form in many different materials, recommend the region of man's creative activity as one where the distinction between matter and form will be most readily observed. It is doubtless for this reason that Aristotle has first turned in his inquiry concerning geneses to the study of artificial production. $\mathrm{He}$ has foreseen, however, the objection that the distinction may have 
been too sharply drawn, and that its practical importance in the world of art may have obscured the analysis. What has been called material may be essential in natural objects as it is in objects of man's fashioning; but a genuinely philosophical analysis might in both cases discover that so far from being distinguished from form it is but a part of the form, and, especially in natural objects, hardly a distinguishable part of it. The question is, can the existence of any or all of the objects of our ordinary experience be essentially nothing but form? Does the intelligible identity, which earlier in the discussion has been admitted as indispensable to the existence of an object, give the complete answer as to what its existence essentially is? To say that it does is utterly to defy empirical observation, and to deny the fact which has given the chief stimulus to reflective inquiry.

Before this result can be fully exhibited, it is necessary to emphasize a doctrine which has been stated earlier and which is to have a considerable influence in the latter portion of the argument. Form as form cannot properly be said to be produced at all. It has been shown that one who makes a bronze sphere does not make the sphere as such, nor was it ever made. ${ }^{1}$

$$
{ }^{1} C f .1033 \mathrm{a}, 32-34 \text {. }
$$


Were forms themselves produced, there would be an infinite regress. In order that the form sphere should have been produced, there would have had to be a preëxistent form, to leave out of account all other requirement; this preëxistent form would similarly have been produced and would demand an earlier form, and so on indefinitely. It might possibly be said that the mode in which the production of the form sphere is to be conceived is merely that its parts existed separately and were at some time assembled. Such a supposition involves an assumption to which Aristotle's thought is almost as hostile as to the assumption of an infinite regress. Every whole that is not simply an aggregate is prior in existence, as in thought, to any or all of its parts. Without the sphere, the existence of the circumference of the sphere is inconceivable; the parts of a sphere are not intelligible-and, if forms, they must be intelligible-without reference to the sphere itself; the sphere is prior to any part of it which we may conceive, and therefore it is clear that the form of sphere cannot have been produced by the assemblage of its parts.

It appears that there is no way in which form as form can be said to be created. ${ }^{2}$ If the truth 
of this be admitted, the necessary conclusion is that a valid account of a world in which change is the conspicuous fact and the one that more than all else calls for explanation, will not be given merely in terms of form. It is placed beyond possibility of doubt that objects which are produced, which undergo change of various kinds, are not in their essential existence solely form. There can be no more undeniable or instructive and important fact than that objects exhibiting distinctive characteristics arise, undergo continual alteration, and finally perish. ' It is true that some natural objects, such as the heavenly bodies, seem permanent; yet even these change as regards position, and so must partake of the general nature of the transitory. The fact of change unqualifiedly demands, in Aristotle's view, something material in that which changes. ${ }^{1}$

A consequence of the view that all existence is essentially form, perhaps even more serious than its unconscious denial of change, is that this view does away with the distinctions existing between the individuals of a class. ${ }^{2}$ The form of the individuals of a given class is generally admitted to be one; although of course it

${ }^{\prime} C f$. 1032a, 20; 1042a, 32 et seq.; 1069b, 3-b, 26.

${ }^{2} C f .1074 a, 33$. 
might fairly be claimed in many cases that the form of an individual is very clearly distinguishable from that of any other member of its class. There remain, however, great realms of existence where the individuals are not evidently different in character and where the closest observation would not avail to bring out a distinction; their intelligible identity is to all intents and purposes and, perhaps absolutely, one. Nevertheless no one has any difficulty, if several members of such a uniform class are placed before him, in telling how many there are; and generally, even if it requires some skill to describe objects, it is a simple matter to distinguish numerically between them. This kind of distinctness would not exist at all if they were essentially form alone. ${ }^{1}$ Different forms might exist; but many of the individuals which now are distinct would be merged in a single form. To do away with matter as an essential factor in the existence of all objects of sense perception is not only to forbid that any change shall enter their existence, but also to deny that they are numerically distinct. Further, it is to offer-noexplanation for the fact that something may chance to emerge in the career of an object which has not been

${ }^{1} C f .1034 a, 7,8$. 
provided for in its form. ${ }^{1}$ Either the form must depart from its nature and include what is accidental as well as what is essential, or matter must be admitted into the definition of the existence of objects, not only that there may be change and complete individuality, but also that there may be some basis in their existence for events not strictly necessitated.

If form as form is not produced, neither is matter, absolutely considered, produced, for it similarly would require an endless series-if it were not unaccountably produced from what was not of material nature. Strictly, matter like form is unproduced. ${ }^{2}$ It remains then to develop more fully how matter and form, which together constitute any individual concrete being, enter into the productive series.

入 There is a sense in which it is said that a particular sphere is produced. A man is said to make a bronze sphere when he clothes the form sphere in the material bronze. Neither the form nor the matter results from the act of making, but only the particular combination of one with the other. In the works of man's art it is clear that to produce is merely to combine in particular ways existing form and existing matter, and so to create an object which did not before exist.

${ }^{1} C f .1027 \mathrm{a}, 13-15$. ${ }^{2} 990 \mathrm{~b}, 12 ; 1069 \mathrm{~b}, 35$. 
The example makes it appear a somewhat natural assumption that before the combination has been made the form existed in entire independence of any matter. One would not be so easily tempted to make a similar supposition regarding the matter, for the diverse materials of which spheres may be made have each a somewhat distinctive character, a form. In the case of the form that is realized in the spheres we perceive, there is a not uncommon tendency to conceive of a sphere of pure form, existing apart from matter. Aristotle claims, however, that if there is such a sphere, it has no particular existence. It cannot be indicated as "this," it can only be described as "such"; number, quality, place and time-whatever limits and defines particular existence-are necessarily lacking in the sphere as pure form. Yet it is said that a man who makes a sphere makes it from the form of sphere, and that when the bronze sphere is made it bears, perhaps imperfectly, the characteristics of the sphere of pure form.

It is true that in a sense existence as pure form is, in works of art, the progenitor of existence as sensibly perceived. The form of sphere which exists in the mind is not, however, independent of the experience of the same form realized in nature, and there is no 
ground whatever for the claim that the form of natural objects exists somewhere devoid of matter. The man Callias or Socrates is analogous to this bronze sphere; man or animal is analogous to the sphere in general. Now, it is clear that if the general form of man-the Idea, as some are accustomed to call it-exists apart from the particular man, this form has nothing to do with the origin or the existence of particular men. ${ }^{1}$

In the case of most of the objects which arise through the reproductive force of nature there is a striking differentiation as to type, which has given rise to the belief that somewhere there exist pure forms, patterns, as it were, for all the members of their respective classes. Leaving out of consideration the obscurity of such an explanation of the similarity among the members of a natural group, the fact is in Aristotle's view sufficiently accounted for by the observation that that which is created is similar in form to that by which it is created - unless nature fails of her usual goal, and even here similarity is apt to be found, if one takes a broad enough view of the matter. Offspring is like parent. Different in matter, they are one in form. It is as in the case of the men Callias and Socrates; they are funda- 
mentally one in form, but this form is in the case of each embodied in a particular set of tissues. The fact of their similarity does not justify one in setting up an ideal Man as exemplar, after which their individual existences have been modelled. Especially for objects in nature, since these most evidently present the character of primal existence, certain philosophers, Aristotle observes, have sought to discover such exemplars. But these exemplars are obviously superfluous. Generally speaking it is indeed correct to say that man is descended from man; but this must not be interpreted to mean that particular individuals of a class have originated from that which itself is not particular.

It has been with the purpose of more exactly determining the conditions under which new existences appear that Aristotle has been drawn into a discussion which anticipates slightly the conclusions of the later inquiry into the universal considered as primal existence. If every genesis is strictly a particular genesis, it may be argued that the essential existence of each being so produced is individual, particular, and not to be explained as merely a detached portion of the universal.

To complete the statement regarding the conditions of change, the ninth chapter of Book Zeta brings into 
closer relation the productions wrought by art and those arising in nature, and shows the correspondence between the conditions of absolute change and those of lesser changes. Of the objects in nature some are relatively inert and can partake of perceptible change only through the application of external force. Production in such cases always requires the intervention of art. Thus the stone requires the work of man's hand that it may be shaped and erected to its place in the structure of a dwelling. Other objects of nature hold within themselves an almost incalculable power of growth and activity. In some cases, however, existences which have the inherent power of growth or action may not be able to grow or act in particular ways; and here art may supplement nature. What art adds, however, may be observed to bear a close relation to that part of the activity of the natural object which it takes as its point of departure. To produce health art selects some material condition which is a part of health or which has health as a natural consequence; as, for example, warmth. Warmth may be produced by friction; hence through friction health may in some cases be established. The creation of health presents at once the characteristics of the productions of nature and the productions of art. As nature, it proceeds from like to 
like; as the result of art, it proceeds from the idea health through the act which will produce it.

Production may be the creation of objects; it may also be the creation of movements and other changes in preëxisting objects. Just as in the case of the creation of objects the form is not itself produced, so in the case of the production of modifications ${ }^{1}$ in objects, the modification as such is not produced. Smoothness in general is not produced in the polishing of wood; what is produced is smoothness of this particular wood. As in the production of objects, the production of modifications in objects consists in the embodying of preëxisting form in preëxisting matter. In the production of modifications in objects, however, the qualities produced need not arise from qualities actually preëxisting. They may arise from qualities preëxisting only potentially.

III

With the close of the ninth chapter of Book Zeta, the outlines of Aristotle's own doctrine of what is fundamental in the existence of objects evident to sense are

${ }^{1}$ Aristotle includes all of the remaining modes of predication. The analysis is thus extended from substantive or primal existence to the so-called secondary or derivative forms of existence. $C$. 1034b, 7-18. 
complete. The remaining eight chapters of the book are, however, requisite for following out certain questions which the earlier chapters deferred. The examination of the use of the term for primal existence as designating the class or the universal has hardly been begun. The manner in which definition is related to primal existence has not been fully developed, and there has been no suggestion of the means whereby that which is both material and form can have any higher degree of unity, and therefore any better claim to being primal existence, than has that which we designate by the expression "white man." This last question is only partially answered in Book Zeta. The discussion of the doctrine of universals has more evidence of finality; while the question discussed at greatest length is that relating to definition. There is at least one excellent reason for introducing at this point a somewhat exhaustive study of the definition. A more advantageous approach to the doctrine of universals could hardly be devised; and it is of course an encounter with that much favored doctrine which an explanation in terms of the particular and concrete must inevitably face.

Among the early difficulties of Book Beta was that concerning the position which genera should hold in philosophic explanation. It was said that inasmuch 
as we know all things through their definitions, and genera are the "originative principles" " of definitions, it may be argued that ultimately genera are the originative principles of the existences defined. ${ }^{2}$ Aristotle has now shown that the objects of nature present forms which are similar to the forms of other objects of the same class but which are embodied in separate and distinct portions of matter. Such objects are, however, represented in thought by concepts which are conveyed through definition. The exact relation of the concept to individual existence evidently needs to be more thoroughly investigated, if the status of the universal is to be less equivocal.

It will be admitted that as the concept is related to the thing, so also the part of the concept is related to the part of the thing. Upon this basis one may then inquire whether the relation of part to whole in the concept entirely corresponds to the relation of part to whole in the object. $^{3}$ It appears that in some cases the concept is not divisible into parts corresponding to the parts of the object; while in other cases the concept is divisible just as the object is divisible. The concept

$$
1 \text { ảoxaí. } \quad 2 \text { 2998b, 4-6. }
$$

${ }^{3}$ This inquiry is made in chapter 10 of Book Zeta. 
circle, for example, is not divisible into concepts of the sections of the circle, although the circle embodied in material may be divided into its sections. The concept of a syllable, however, is divisible into the concepts of its elements, just as the syllable is divisible into its parts. The concept of man again is not divided into concepts of bones, sinews and muscles. All concrete objects, as has been shown, represent a union of form and matter. While matter is a part of the concrete object, it does not form a part of the concept. The bronze is a part of the statue as an object; it will be indicated in a description, but strictly it forms no part of statue as a concept.

From this line of argument. Aristotle concludes that form, and form alone, can be expressed in the concept. It is for this reason that the sections of a circle, though parts of an actual circle, are not parts of the concept circle. Again, the concept of acute angle forms no part of the concept right angle, although a material object having the form of a right angle may be divided into acute angles. In concept the circle is clearly prior to the sections, and. these are definable only with reference to it. The right angle is not defined with reference to the acute angle, but the acute angle with reference to the right angle. 
Aristotle has indeed held that the concept of the syllable may be divided into the concepts of the letters; but by the letters he means not the letters as made in wax or as articulate in speech, but only as intelligible to the mind. Only those parts which are immaterial can be parts of the concept. Matter, as has been said before, is indefinable and necessarily eludes conception.

In so far then as an object is material it must escape conception and the expression of conception in definition. Individual objects, since they are in some degree material, will never be adequately represented by definition. ${ }^{1}$ They may be perceived and indicated but they can be defined only through the universal, which ignores an essential part of their existence. A particular circle can be defined only in so far as its form is that which is universal among circles. Its individual existence is of the matter, not of the form, and form alone can appear in definition. ${ }^{2}$

Since the definition has to do with the form alone it is evident that valid definition must be based upon a clear distinction between the form of an object and its material. ${ }^{8}$ Clarified concepts require an unerring

${ }^{1}$ Cf. 1036a, 2-6.

${ }^{2} C f .1036 \mathrm{a}, 28,29$.

${ }^{3}$ This problem is considered in chapter 11 of Book Zeta. 
recognition of form. Where the same form is found under diverse material embodiments, as the circle in bronze and wood and stone, the mind readily distinguishes the form as such. Where, however, the form is regularly embodied in the same material, as the form of man in bone and sinew and muscle, the distinction is not an easy one. ${ }^{1}$

${ }^{1}$ Aristotle discovers in this general fact the reason that some philosophers have held that the circle and the triangle may not properly be defined by lines and the continuous. These elements seem to them analogous to the flesh and bone of man and to the bronze of the statue; they consider them material and accordingly regard number as the true form. The concept of the line, for example, is according to their view that of the number two. They are not agreed as to whether the Dyad is the line itself or only the form of the line. By this method, Aristotle remarks, many things which appear to differ in form are reduced by the Pythagoreans to one and the same form. Carried to its logical conclusion, their method would result in reducing all things to a single unity. Accordingly the futility of the method is self-evident. Its_initial mistake is evidently that of assuming intelligibility as the supreme test of existence. With such a criterion, all that falls short of universality is degraded, and the individual and particular becomes almost the non-existent. In opposition to such doctrine Aristotle affirms that the universal does not exist apart from individuals, that the definition faithfully records only a part of the existence of that to which it applies, but that it is still necessary to regard the definition as primarily applicable to existences which are individual. 
If examination be made of a definition, which, as has been shown, is capable of analysis into parts, it is found that it contains nothing but the genus and the differentiæ. ${ }^{1}$ Whether there is one differentia or many, Aristotle says, makes no difference. In either case the definition reached is a unitary concept. The question may arise, In what consists this unity? It may be asked why the concept expressed in definition, as applicable to primal existence, does not break up into independent concepts, as it was shown occurs in the case of such a concept as that of white man. Man, it was said, is not necessarily white, whiteness can be conceived apart from man; therefore the concept of white man is a complex of two independent concepts and is not strictly definition. Why now is not the concept biped animal, which may be allowed to repre-

${ }^{1}$ This term is so used as to include the various grades of division to which the genus is subjected. The way in which a definition is properly constructed is thus exemplified: animals may be differentiated as the footed and the footless; footed animals, again, may be regarded as a genus which may be differentiated into the twofooted and many-footed; following the direct line of differentiation, one should next take as genus the two-footed and differentiate according to the characteristics of the foot-as to the division of the foot or its lack of division; thus one should proceed until he arrives at that which is no longer capable of differentiation. 
sent the definition of man, equally capable of analysis into independent concepts? The question evidently bears upon the unity of what is defined. ${ }^{1}$ It is clear, however, that biped cannot be conceived as existing independently of animal. Biped then implies the concept of animal; but not in the sense that it is the same concept as that of animal, since there are animals that do not possess this characteristic and it would be absurd that the same concept should contain contradictory characteristics, as if animal were at once quadruped and biped. Similarly it may be argued that the concept wingless biped animal is one; for winglessness characterizes a certain kind of biped animal. It is again not a mere repetition of the concept biped, since not all bipeds are wingless. The definition may accord ingly have numerous parts, and yet be strictly unitary if it is constructed according to the fundamental characteristics of that which is defined and does not contain what is merely accidental. As the genus does not exist apart from the differentia, nor this apart from its differentiæ, if it have such, it is clear that, if in constructing a definition one has proceeded directly in the line of essential differentiæ, the last differentia best 
indicates actual existence, and the concept which contains this last differentia better satisfies the requirement for the concept of the form of any primal existence than does the concept of the genus or a higher universal.

IV

That which constitutes the existence of an individual object is that which is characteristic of that particular object and which is not shared by any other object. Now the universal is by definition that which is common to a class. I Were the universal regarded as primal existence it would have to be called the primal existence either of all the objects of any given class or of none of them. Of all it could not be; for assume that it were the existence of all, then all the objects of the class would be reduced to one, according to the rule that that is one the primal existence of which is one; and the universal as universal and not partieular would no longer exist. Again, if it be assumed that the universal is the primal existence of any one of a class, Aristotle argues that for the same reason all the others of the class become that one, and the universal again disappears. ${ }^{1}$

The existence of the universal may, however, be some-

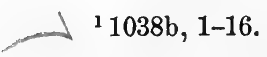


what differently conceived. It may be proposed that the universal exists in a way analogous to the existence of the form of man in Callias, Socrates and others. Thus, may there not exist a universal "animal" appearing both in man and in beast? To arrive at the concept man it is indeed necessary to consider particular men devoid of their accidental characteristics. But it cannot be said that what differentiates man and beast is accidental. Socrates, it has been said, would remain a man though he were deprived of culture. On the other hand a particular animal would not remain the same if deprived of the characteristics differentiating man and beast; these characteristics cannot be regarded as accidental.

Nor is there any other way of adapting the theory of universals to the facts. What the universal in. truth designates is the common possession by a variety of objects of some one quality or characteristic. Thus a quality of man is expressed when we say that he is an animal; a further quality when we say that he is a biped. Those who hold that the individual is made up of universals, as man of biped and animal, must assert-if universals indeed are of qualitative rank as Aristotle regards them ${ }^{1}$ - that the

$$
{ }^{1} C f .1039 \mathrm{a}, 1,2 .
$$


qualities are prior to that which bears the qualities. This is obviously absurd, for if the qualities were prior it would be necessary that they should exist separately - biped, for example, would have to exist somehow by itself, apart from all animals that are biped. Assuming for the moment that the universal designates not a quality shared in common by a class of objects, but primal existence, Aristotle argues that then Socrates, being man, biped, animal, would be not one but several, for primal existence is always separate and individual. Socrates, then, if he is one cannot be composed of several distinct primal existences. ${ }^{1}$

The view that primal existence is always individual has, however, from the standpoint of definition an obvious difficulty. The prevailing opinion among thinkers, the one which Aristotle says is correct, is that definition is of primal existence-if not entirely, at any rate chiefly. But if primal existences are simple, if one cannot be affirmed of another, does not definition of primal existences become altogether impossible? If for example biped and animal as such are non-existent, the definition of man as a biped animal seems to be not a definition at all. And this consideration points to an

$$
{ }^{1} \text { Cf. 1039a, } 4 .
$$


apparent advantage enjoyed by those philosophers who regard universals as primary existence.

If, however, the Ideas exist as primary beings, if perhaps the Animal exists in man and horse, it may be asked if this Animal is one and the same in both man and horse, or is there a different Animal for each? If the-answer is that Animal is one and the same to the degree that you are one and the same with yourself, ${ }^{1}$ we are confronted with the absurdify that one and the same thing possesses contradictory characteristics; the same thing will be both biped and quadruped. XAgain, this view requires that the same thing exist in different beings; what reason then is there for assuming that Animal itself will exist in itself and not apart from itself? If, on the other hand, the Animal existing in man is not one and the same with the Animal existing in horse, the varieties and number of the universal Animal must be thought to be infinite. ${ }^{2}$ Again, what relation would the universal Animal bear to the particular concrete animal which is the object of experience? By assumption the universal Animal is primal existence and independent of the concrete animal. It would be necessary, then, for it to be at once itself and 
the concrete animal besides. Perhaps it may be said that the concrete animal participates in the universal or coincides with it; but these expressions Aristotle pronounces to be utterly without meaning.

Now it is true that the concrete individual, ${ }^{1}$ that which Aristotle has declared is primal existence, in an important sense eludes definition. ${ }^{2}$ Whatever is concrete and individual comes into existence and passes away. When the individual is beyond the range of our sense perception we cannot certainly affirm that it exists; and this is because the concrete is composed of form and matter, and the nature of the combination is such that it may either be or not be. Science deals not with that which may both be and not be-for that would degrade science to the rank of opinion-but with the necessary, with that which always retains its characteristics. There can then be no definition or demonstration of the concrete individual. Whenever one assumes to define a concrete individual he must not ignore the fact that it is always possible that he may be refuted through the disappearance of the object of his definition. $^{3}$ A particular house cannot be defined scientifically. House in the sense of intelligible form

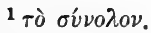

$$
\begin{aligned}
& \text { 21036a, 2-6; 1039b, } 28 . \\
& { }^{3} \mathrm{Cf} \text {. 1040a, 5-7. }
\end{aligned}
$$


may be defined, since, as has been shown, it is not produced nor is it destroyed. Now those who have advocated the existence of the universals have represented them as if they were individuals. It can accordingly be shown that if Ideas, in this sense of universals which are individuals, exist, they are no more capable of definition than is the concrete object. ${ }^{1}$

Such Ideas, it will have to be admitted, are either simple and unique or composed of parts. In the latter case a definition would not apply to any one Idea, but would apply to all that were composed of the same parts. If the Ideas are unique, where would one find terms with which to define them? He cannot invent them, Aristotle urges, for they would be unintelligible. If he takes them from common speech, the terms will apply not to the one being alone, but to others likewise. It may possibly be said that by enumerating the characteristics in sufficient detail, a definition may be obtained, the terms of which taken together can apply to only one object, although any one of these terms may apply to a number of objects. In arriving at a definition in this way, however, one would enumerate characteristics which are accidental and which if taken away would leave the object of definition still the 
same object. It is therefore evident that a definition so formed is not truly a definition.

Furthermore, even if a definition could be made applying to one object only, yet another object might arise possessing the same characteristics, and the definition would no longer be exclusively of the one. An example will serve to make this clear: If one were to attempt to define the sun, might there not conceivably arise another sun to which the definition would be equally applicable? If one defined the sun as "the one going around the earth" or the "nightly concealed," he would rely, Aristotle asserts, upon an accidental characteristic; for the sun might stand still or always appear in the heavens and it would still be the sun. - The Ideas, or universals regarded as individual existences, cannot be known through definition. They cannot be known as any concrete object of experience is known, since they are by hypothesis withdrawn from sense perception. There is then no evident way in which they may be known at all.

The criticism of universals regarded as primal existence is extended in the sixteenth chapter of Zeta to the highest universals, Being and Unity. This discussion is introduced by a brief inquiry into what constitutes the unity of an existence. It is indicated that every in- 
dividual has a reason for its unity as well as for its being in something else than participation in a universal Unity or Being. What precisely the reason is, remains a subject for later inquiry, although it is here vaguely suggested. Certain of the existences which in former passages were included in the enumeration of what are generally regarded as primal are now said to be only the potentialities of individual existence. Such, for example, are earth, fire and air; they are, in the figurative language that is employed, "as the milk before it has thickened"- the materials which may be imbued with a form. The parts of animals likewise are to be regarded as giving merely the potentiality of individual existence, for none of these exist separately from the animals, and if they are separated they are as matter. ${ }^{1}$ Primary existence must present the char-

${ }^{1}$ Yet in some cases, Aristotle observes, it may seem that the parts of animals come near possessing individual existence, actual as well as potential; this is when the parts have principles of movement from certain points within themselres, and is most striking in those cases in which, although separated from the body, the parts continue to live. Nevertheless, instead of being called themselves individual existences, the parts of animals are rightly regarded as the potentiality of individual existence, in all the cases in which they are one and continuous by nature and not held together by external force or accidental adhesion. 
acteristic of unity, but whatever may truly be called unitary must be said to exist. It is clear then that neither existence in general nor unity in general can be the primary existence of the individual object, since nothing that is universal is primary existence. It hardly needs to be said that individual existence belongs only to what exists individually. Being and unity, however, are attributed to all things; these are the most universal characteristics of all, and hence farthest removed from concrete existence.

I Those who assume that the universals are primal existence are not to be criticised for having attributed to them independence, for without independence primal existence is inconceivable. Where they are evidently at fault is in assuming that the Idea, by hypothesis one and actually existing, is at the same time the essential existence of the many. ${ }^{1}$ That there are eternal

${ }^{1}$ There is in Aristotle's opinion a ready explanation for the origin of the doctrine of the Ideas. The reason it is assumed that such imperishable existences as the Ideas are like perishable concrete objects of experience is that it is not clearly understood what the nature of the eternal and imperishable must be. It came about that those who were unduly abstract in their thinking imagined that they had discovered a fundamental reality if they had been able to conceive of horse in itself or man in himself, when all they did was to attach the words in itself to names of common objects. 
and imperishable existences which are beyond the range of sense perception, it is far from Aristotle's purpose to deny; he says that the stars would none the less exist eternally if human beings were entirely incapable of seeing them. To know the nature of the eternal existences requires, however, another process than the striking of imaginary copies from the objects of sense perception. 


\section{CHAPTER VI}

The Unity of Matter and Form-Potentiality

\section{I}

The study of definition, leading as it does to an evaluation of the philosophical doctrine of universals, has enabled Aristotle emphatically to re-affirm that it is the individual which in the truest sense exists, even if de-

finition cannot report the whole of that existence. Primal existence then consists not in the universal, not in the form of disembodied Ideas, but in the concrete and individual. There remains the question as to how that which is made up of matter and form, as it has been shown the concrete must be, can be genuinely one. $^{1}$ To this question, for apparently two reasons, Aristotle now gives special attention. Natural geneses, as well as creations in art, have been viewed as particular combinations of matter and form. How, on the ond hand, is combination of matter and form at all possible? and, on the other hand, how is it that absolute exclu- 
sions subsist between certain kinds of matter and certain forms, that everywhere partialities and preferences are evidenced? There is a generic question involved, and also one that is special. Empirically, the analysis already made is all that it need be; it fairly recounts the facts of origin, and it can readily be applied, mutatis mutandis, to relative, or lesser change. It has exhibited what is essential to any of the independent, or substantive, existences which we encounter in ordinary experience; it has declared with good show of reason that primal existence is definite, individual.

On logical grounds, however, it may be urged that an object which is one cannot be both matter and form. This question is approached with great deliberation; various possibilities of explanation are suggested through a general consideration of the modes in which the union of different factors may be stated. Explanation, it is said, ordinarily consists in affirming one thing of another. ${ }^{1}$ To affirm one thing of itself is pointless. One cannot, for example, raise the question why man is man, for the answer is included in the question; or, otherwise regarded, there is but one answer for all such questions. One may properly ask, why is man an ani- 
mal; for this may be answered by the statement that man has such and such characteristics. In this and all similar cases the existence of man is assumed in the question, and this points to the primary nature of man.

But explanation may also mean the laying bare of the efficient causes of a phenomenon. It may be asked why a particular object is composed as it is, meaning what causes have produced it. Thus it may be asked why these stones and tiles are a house, the meaning being, by what means did they come to be combined into a house.

Again, explanation may take the form of reducing an object to its elements. Flesh may be composed of earth and fire. It is nevertheless not merely earth and fire; the combination is something quite different from its components. For imagine flesh reduced to fire and earth; it becomes fire and earth, and is flesh no longer. But assume that there is a third element $x$, which together with fire and earth make flesh. Yet when considered as fire and earth and $x$, flesh is no longer flesh, but these; one would then need a fourth element, and upon being granted it, would meet with the same difficulty, and so, on indefinitely. It is clear then that it is not through analysis into elements that the unity of a concrete existence can be ex- 
plained. The suggestion with which Book Zeta closes is that the explanation of the unity of the individual existence lies rather in something which is not an element and which, since it exists according to nature, may be called the nature of the object. This unity of matter and form is what is meant by its fundamental existence.

Book-Eta continues the discussion regarding the unity of matter and form in the primal existence. ${ }^{1}$ It must be admitted in the first place that all sensibly perceived objects presuppose matter. All such objects come into being and perish or are at least in some way subject to change. They increase and diminish in size, they pass from place to place, they may in many

${ }^{1}$ It is possible to regard the book as little more than an appendix to the extended discussion of the preceding book, in which the theory of the fundamental existence of objects evident to sense has been almost completely developed; in this light it would be in its first five chapters a fragmentary reënforcement of certain points of the argument given in Book Zeta, and its closing chapter would appear simply to prepare for the discussion of Book Theta. Yet the selection of its topics and their development are such as to make it more probable that the book fulfils a distinct purpose; the question bearing upon the unity of matter and form in the individual object receives a conclusive answer, and there is nothing to show that Book Eta does not owe its existence to the importance which evidently attaches to this question. 
cases undergo multiform modifications. All this would be impossible were there no substrate ${ }^{T}$ remaining the same with itself through the change. This substrate, in assuming positive character or in suffering deprivation of character, possesses the quality of potential though not actual concrete existence; this it is which is meant by matter. Democritus held that the differences in objects sensibly perceived originated in three differentiating characteristics of a substrate material; the matter was homogeneous in nature but was subject to differences in shape, position and arrangement. Aristotle claims, however, that the differentiating characteristics of objects are manifold-such, for example, as synthesis, position, time, place. All these characteristics and more go to make up individuality. They themselves are of course not fundamental existence, but such existence appears to require their presence.

After the argument of Book Zeta it can not be doubted that the objects of sense perception have both matter and form. ${ }^{2}$ If, for example, soul is the form of

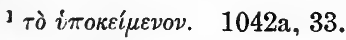

${ }^{2}$ It is true that the question may sometimes arise whether the name of an object signifies the form alone or the composite of form and matter; but if the inquiry is, what exists, the form alone does not explain a concrete existence. Cf. 1043a, 29 et seq. 
man, the soul is yet not man; but soul in body is man. How now shall one rightly conceive of the soul as in the body-of the unity of that which is both matter and form? It does not seem to carry much weight to say that man is composed of body and soul by synthesis. Nor is there any significance in asserting that a man is composed of body and soul together with a third element, which may perhaps be called synthesis. Synthesis does not on the one hand arise out of the things synthesized, nor on the other is it wholly independent.

The very unity of the definition appears to rest upon the unity of the object whose kind it defines; ${ }^{1}$ yet the object contains that which must be left unanalyzed by the definition. This may be the reason why no ground for the unity of the definition appears within it; and yet it undeniably is one not by a loose attachment of part to part, as the Iliad, but somehow vitally one. ${ }^{2}$ Aristotle finds an analogy between definition and number. ${ }^{3}$ Each is in his view made up of elements which are themselves not further resolvable; each ceases to be itself when any element however small is either added or withdrawn. Leaving aside the unity of number, the

'1037b, 26; 1044a, 6, 7 .

${ }^{2}$ Cf. 1045a, 12-14.

1043b, 34; 1044a, 11. 
unity of definition is observed in last analysis to rest upon the unity of the object whose kind is defined. In what then does this unity consist? In the case of such an object as man unity is not made the more intelligible by such expressions as the 'intercourse' of soul and body, their 'synthesis,' a 'participation' of the one in the other; these are empty phrases.

The question as to how matter and form are united is an entirely legitimate question, and yet one which requires the importation of no new agencies, no extraneous factors, which merely falsify the situation. The terms of its answer are already given, and need only to be clearly stated. It is well to observe, however, that the question can be variously understood. In seeking to know how that which was material has been enabled to take on form, we may make the empirical observation that without the agency of some maker this material would not have been so formed; and we may so far forth truly say that matter and form have here become one through the activity of the efficient cause. This reason for the unity of matter and form was explicit in all the discussion regarding geneses. It is at best an empirical answer and contributes nothing to the ultimate problem as to how the object composed of matter and form is one. An answer which is of the type now de- 
manded, but which at the same time is not very illuminating, is to say that matter and form constitute an object which is one, because such is the "nature" of objects. ${ }^{1}$

In the study of definition, which has throughout an important bearing on the doctrine of primal existence, Aristotle has endeavored to elucidate what constitutes the unity of the definition. The result has not, however, contributed towards a more complete understanding of the unity of the object, for the unity of definitious has been shown to depend precisely upon the unity of the respective objects to which the definitions apply. Apparently there is no indirect means of getting at the unity of the object, and if instead of the vaguely general explanation " nature," we are to have a truly intelligible and appropriate statement of the unity of matter and form, it will be by appeal to what is logically involved in any instance of concrete, individual existence. Aristotle bas indicated that if it is difficult to explain how two factors constitute a unity, the task can be made none the easier by assuming in the object a third factor, be it material or activity, whose duty it is to unite the other two. For were this conceded, there would nevertheless exist a disjunction ${ }^{1} C f .1041 \mathrm{~b}, 30$. 
between the two original factors on the one hand and the tertium quid on the other, to say nothing of the difficulty of exhibiting the nature of the latter.

It is an exemplification of Aristotle's desire for completeness in theory that he is not content to leave the doctrine of change logically undeveloped. As it stands, this doctrine has, in addition to the general weakness that the very possibility of change may be called in question, the particular vulnerability that no explicit provision is made for characteristic change. To find a logical basis for change in general and for the specific character of change the discussion turns to the complementary concepts of potentiality and actuality.

If change is anything more than the fortuitous juxtaposition of unrelated states, if it is to be considered as in any sense a process, as something continuous, and in some way consistent with the nature of that which changes, recourse must be had to the notion of the potential. Without it we shall see merely discrete moments of existence destitute of relation to one another; anything might appear at any time, abruptly ushered into existence and as abruptly ushered out; there would be no organic connection between what now exists and 
what will be, no vital dependence of what is upon what has been. Similarly, if there were not different potentialities, special capacities, distinct fitnesses, anything might come from anything; there would be no predictable lines of action, and no maintenance of classes; there would be no characteristic processes. Genesis, development, change of any kind, can not be intelligibly represented apart from the distinction between the potential and the actual; and of the same necessity, with the recognition of kinds of change thought admits special potentialities. ${ }^{1}$ Only in this way is a basis in theory afforded the facts of empirical observation.

We observe that an object which was not has arisen; it was not produced from nothing, but from a preëxisting material which was potentially the object. A being already existing will take on new qualities, altered magnitude or figure, new activities; reason requires that the being now possess the potentiality of theseor, in the less circuitous way which Aristotle prefers, that it be the potentiality of these, just as the material of which an object will be composed is the potentiality of the object. And note again, to admit a merely general potentiality will nowise suffice. Actualities are many and diverse; equally so are the complementary

${ }^{1} C f .1043 \mathrm{a}, 12$. 
potentialities. We do not find unlike realizations emerging from identical antecedents, but always a specific result, be it event or object, from what was itself particular; and our account of change is the more scientific, the more it recognizes special potentialities.

\section{III}

As the original inquiry into change was instituted for the sake of what it might disclose regarding primal existence, so the distinction between the potential and the actual, which Aristotle has discovered to be logically involved in the concept of change, has a value for the more complete statement of primal existence. The analysis disclosed that the kind of existence manifested by any of the objects which surround us-the kind which we ourselves are, as constituted of soul, or life, and body -is a combination of matter and form. And now the terms in which the unity of the object is rightly conceived are shown to be no other than those which are logically required by the concept of change. If it be asked how at the same time an object is both matter and form, the simple and adequate answer is that potentially considered it is indeed matter, but actually it is form. ${ }^{1}$ The material tissues of the human ${ }^{1} C f .1045 \mathrm{~b}, 16, e t$ seq. In the case of objects that are produced and 
body are potentially man; and when animated by the soul become man actual, and the two are thus one. To this answer regarding the unity of objects evident to sense, Aristotle adds that in the case of existences devoid of matter which yet are individual, if such there areas indeed it lies within the purpose of his argument to show-since these are neither produced, destroyed nor subject to any change, but are eternal, there is no analogous cause for unity. Such beings have unity as they have existence, and it is not reasonable to demand) a further cause for their unity.

Potentiality and actuality are for Aristotle but the two faces of the identical reality, the two aspects which everything that is in any way subjected to change must inevitably possess; and the analysis which arose in response to a demand for logical completeness has become his most considerable philosophic contribution. The constant recurrence in the middle portion of the Metaphysics of the question regarding the unity of an object, the great pains at which Aristotle is to consider it from many points of view, cannot be passed over as of trivial importance for the main development. Here indeed is

perish there is, in Aristotle's view, no other cause for unity, unless indeed reference is made to that cause which results in the embodiment of form in matter, the creative act. 
the pivotal conception. Although the question arose in an inconspicuous way, and receives at first but inconclusive answers, there can be no doubt as to the importance attached to a final answer which shall be adequate. Without it Aristotle's philosophy might have disintegrated and would at best have been subject to a multiplicity of misinterpretations.

There needs to be this unqualified rejection of mysterious mediation between matter and form. There needs to be this further definition of what in fact is meant by matter and by form. Apart from the historic interest in the problem of the many and the one - upon which the solution is observed to bear-there is an ever present question as to the relation between the character of an existence and the material whereon this character reposes. But in Aristotle's system this

question is no longer perplexing; it has its solution, as the nature of existence its ilfumination, in the conception of the actual as but the awakened potency of the material, which is, strictly speaking, the promise of form to be realized. In point of fact, matter never exists unformed; but it is always capable of altered disposition, and regarded in the light of that which it is to be, may be considered as matter, mere potentiality. It is also true that if there is to be-an-awakening, a disposing, 
there must be that which awakes, that which disposes; and this agent, Aristotle says, is necessarily a being already actual, or, in narrowest regard, it is an activity.

It remains to make note of certain conceptions that are obviously alien to this kind of thinking. Inert matter, for example, whether merely for the time being devoid of activity or wholly incapable of it, is not admissible. For Aristotle there is no matter which does not now and always possess some kind of form. It is true that there are materials which have the lowest degree of organization and which cannot be expected to assume complex forms; but still, such as it is, they have their form. They can be considered as mere material only in abstract thinking and as distinguished from the form they now possess or with reference to that which they may assume. The notion of matter devoid of possibility of form is utterly rejected; matter is for thought just the potentiality of realizing form.

The relation of form and matter in primal existence, in any object with which sense perception acquaints us, is not to be viewed as a loose attachment; the form does not mean merely the traceable contour, the vital network in which are swung loose bits of matter. Nor is the form only an apparent show, which results from the agglomeration of material atoms, the variance of 
the show being due solely to quantitative and spatial variations. Form is function, not mere appearance or mental residuum. One may say if he likes that it dominates matter, controls, "informs" it, if such expressions do not beguile him-into the deceptive notion that the form resides in a chief part, whence its control in some indeterminable way extends throughout its territory. This not uncommon fallacy issues in the negation of all that is meant by form. When the form is conceived as having definite location it will almost inevitably be thought of as occupying space; and if spatial, therewith material. The soul, properly conceived, is the body's life, form; there is no portion where it may be said exclusively to dwell, for it is the body's function. As the body has its various members, the soul has its different activities. It is the complex but unified life of a complex body. The only valid conception of form is function, activity.

\section{IV}

In view of the argument in Books Zeta and Eta there can be no doubt as to the importance of the concepts of potentiality and actuality, both for a complete statement of change and for a final account of the relation between matter and form in concrete existence. 
It is therefore not surprising that Book Theta-with the exception of its tenth chapter, which belongs to an earlier discussion concerning the true and the false-is devoted exclusively to the consideration of the potential and the actual. In the preceding study it has appeared that an explanation of changing existence must recognize the possibility of existence which is not yet but which will be, of matter relatively unformed and capable of taking form. As distinguished from actual existence, such possible existence Aristotle has designated as the potential.

The actual appears most conspicuously as motion, although its manifestation is here imperfect, and it is better exhibited as function. The potential Aristotle classifies under two heads: the capacity resident in an object of bringing about change in another or of actively inducing change in itself; and the capacity of an object for undergoing change through the action of another object or through its own activity directed towards itself as object. In Aristotle's usage what, for want of a better term, may be called active potentiality is the capacity of producing change in another, while passive potentiality is the capacity of suffering change through an external agency.

The potential exists in both animate and inanimate 
beings. Especially does it appear in the human soul as a power to do, which exists even when not called into action. The arts and sciences as such are powers of this nature, since they are capacities of producing definite change. The builder has the power of constructing a house even when he is not actually engaged in the work of construction. Aristotle is enabled to make a distinction between potentialities upon the basis of their dependence upon reason, on the one hand, and their independence of rational control, on the other. The capacities just exemplified may be called rational, while other potentialities not within control, especially those of inanimate objects, are non-rational. ${ }^{1}$ The non-rational potentialities or powers are strictly determined as to their effects; while it is a mark of the others that they may produce directly contrary effects. Thus the potentialities of non-rational agents are narrowly determined; a warm object merely produces warmth, a cold object produces only cold; and they cannot possibly produce the opposite effects. A healing drug is limited to producing health. The science of medicine, on the other hand, may be employed to produce effects opposed to each other. One who has

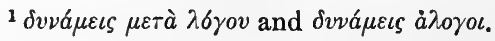


the art of producing health possesses also the art of destroying it; and the reason of this is the fact, made familiar in earlier discussion, that science is based upon concepts and any concept implies its opposite. The soul, as it is generally recognized to have in itself the power of originating action, may set in motion events that will result in either conceived end.

In view of the failure on the part of some thinkers to recognize the existence of the potential, Aristotle finds it necessary to show the consequences of neglecting to take it into account. ${ }^{1}$ The Megarians, for example, have denied that there is any power except in its exercise. According to them a builder cannot be said to be able to build except when he is in the act of building. Of course it is clear that there cannot be a builder who does not build at all; but what in Aristotle's opinion. characterizes the builder as such and distinguishes him from other men, is his ability to build, not the accidental fact that at a particular time he is building. $\mathrm{He}$ argues that if there is, for instance, a builder's craft, which men must learn before they can exercise it and which does not normally pass out of the possession of those who have once learned it, the craftsman must

${ }^{1}$ Chapter 3 of Book Theta. 
possess it as mere power even when he does not exercise it. Otherwise it would be necessary for the builder to learn his craft anew whenever he undertook to build, and to forget it completely as soon as each task was completed. The same would be true of all arts. In like manner it may be maintained that if one who is seated has no power to rise he must forever remain seated, and one who stands must always have stood. So also objects that are hot or cold or sweet or in any way capable of perception will not possess those qualities when they are not in process of being perceived. Moreover those who do not perceive can have no power of perceiving; and one who has normal organs of vision, since he does not always exercise those organs, will be blind several times a day. In general, then, it may be said that those who limit existence to the actual take away all possibility of change, of coming into existence and of perishing. It is accordingly no unimportant portion of existence that they thus seek to eliminate.

It is necessary to distinguish, however, between what is possible in the sense of being able to come into actual existence and what is possible in the sense of being merely conceivable but incapable of realization. By he potential is meant that which is not actually existng but which will exist if certain conditions, as time, 
place and the like, are fulfilled. It is unfruitful to regard something as possible which nevertheless could never be; this indeed destroys the significant distinction between the possible and the impossible. More clearly to define his conception of the potential, Aristotle says that potentiality is truly predicated of an object which when brought into connection with an object of complementary potentiality necessarily acts or suffers. For example, when an object of active potentiality is brought into connection with one of a corresponding passive potentiality, the former acts and the latter suffers. ${ }^{1}$

It may now be inquired under what conditions the thing which does not exist actually may be said to exist potentially; under what conditions that which is still material may be said to be potentially a material imbued with form, or the actual. It seems clear that it is hardly an exact use of language to say that the ore fresh from the ground is potentially a statue. Under certain conditions the ore may become bronze; and bronze

${ }^{1}$ In the case of inanimate objects the result of such juxtaposition is always determinate. In the case of the rational being possessing potentiality, since such a being has it within his power to produce opposites, the result involves a choice between two possible ends; and the end chosen becomes actual, to the exclusion of the other. Cf. 1046b, 4-24. 
may be regarded as potentially a statue, since it may directly become such under the artist's hand. If again the ore is derived from something still more primitive, perhaps earth, that more primitive matter is potentially ore.

A clue to the potential is afforded by a certain common method employed in describing the actual. It is said, for example, that the chest is wooden, the vase earthen; wood and earth are thus indicated as substances capable of being given the form of chest or vase. The actual may be described as the antithesis of the potential. The actual is related to the potential as the Hermes is related to the slab from which it was hewn or as movement is related to power to move. ${ }^{1}$

${ }^{1} C f$. 1048b, 8, 9. Not all movement or action, however, presents the character of complete actuality. Some morements are in themselves the end toward which they are directed; the activity of thought, for example, is complete within itself, one who thinks is by that very act in possession of thought. On the other hand, many actions and movements are directed towards some end outside of themselves. These Aristotle calls incomplete; they cannot be said to possess actuality without reference to the ends which they accomplish. Thus the activities of house-building have no actuality apart from the house, the object towards which their action is directed. 
An important part of Aristotle's doctrine is that the actual, although by no means the whole of existence, holds the rank of priority in existence. ${ }^{1}$ It is prior in thought, it is sometimes prior in time, it is always prior in essential nature The actual is prior not only to the potential but to every beginning of being. Nature itself, according to which concrete forms of existence unfold themselves, may from this point of view be placed in the same genus with potentiality. Natural process is conceivable and has meaning only with reference to the actual and complete which arises in accordance with it.

The priority of the actual as to concept is evident. Capacity to act or suffer in a certain way-to build, to see, to be seen-can be understood only by reference to the act of building, of seeing, the actual fact of being seen. Priority in time is in some cases not less evident. In order that a particular animal may exist potentially, it is necessary that there should be an animal of like kind at an earlier time. An actual plant does indeed rise out of the plant existing potentially in the seed; but this implies a plant of like

${ }^{1}$ Chapter 8 of Book Theta. 
kind existing actually at some earlier period. And if this too has arisen from a plant existing potentially in seed, nevertheless in tracing back the generations we must arrive at last at some first individual existing actually.

The priority of the actual as to essential nature is also clear. The man is in this sense prior to the boy that he once was, for the man embodies the form of a developed soul. The form of the boy is evidently incomplete, since the boy through the normal course of nature develops into man. Further, anything which is produced proceeds toward an end; and, as the whole structure of Aristotle's thought requires, this end is not the potential but the actual. The power of sight, for example, exists in order that the animal may see; the animal does not see in order that it may have the power of sight. The capacity of building exists in order that houses may be built. The power of reflection exists in order that men may reflect; men do not reflect in order that they may have the power of reflection, except perhaps in so far as this is done for the sake of further training. This priority of action as compared with mere power to act is indicated by the attitude of the teacher. $\mathrm{He}$ considers that he has not attained his purpose until he has exhibited his students, 
not merely possessing the power to act upon his precepts, but actually acting upon them.

This argument for the primacy of the actual prepares for the transition from the consideration of existence evident to sense to the consideration of the unperishing. The claim is that things eternal are prior to things perishable, and nothing eternal exists potentially. All that is potential as to its existence may either be or not be. What may cease to be is perishable. Whatever is eternal may possibly manifest potentiality with respect to quality, time or place; it cannot manifest potentiality as to its existence. Accordingly, whatever is eternal is actual; and it is first in the order of the universe. It exists necessarily, for were this not true it would be possible that nothing should exist at all.

If there is movement which is eternal, as the heavenly movements appear to be, such movement cannot be potential but must necessarily be actual. An eternal motion is not subject to interruption; although Aristotle sees no reason for excluding potentiality with reference to the direction of the motion. He claims that there can then be no ground for fearing, as do the naturalists, that the sun and the other heavenly bodies will some time cease to move; for these do not become exhausted as do perishable bodies in motion. The 
perishable bodies being subject to potentiality may move or may not move; and this is why they become exhausted. ${ }^{1}$

In estimates of worth the actual again manifests its superiority to the potential. That which is actually good cannot be otherwise, but that which is potentially good may be otherwise. Things eternal, being actual, are not subject to fault or corruption. Their worth is eternal, unchanging.

${ }^{1}$ Earth and fire Aristotle observes are, of terrestrial bodies, most like the eternal, for they hold within themselves a constant action. 


\section{CHAPTER VII}

The Ideas and Mathematical Entities.

Among the questions proposed in Book Beta the one relating to the existence of beings not evident to sense was given a place of prominence. To this question the last three books of the Metaphysics may be considered an exhaustive reply. ${ }^{1}$ It is shown that with the completion of the inquiry into existence evident to sense, the study of existence as such is by no means con-

${ }^{1}$ In the first chapter of Book Lambda the discussion of the question is formally opened. The four succeeding chapters of the book bring together the results of the investigation into primal existence evident to sense; it is then possible in the sixth chapter for Aristotle to begin the statement of his own view concerning primal existence beyond the reach of sense. This statement occupies the remainder of Lambda, and Books $\mathrm{Mu}$ and Nu undertake a thorough criticism of important opposing views. There is some reason to believe that in the original plan the discussion of Lambda was designed to follow that of the other two books. Cf. Christ's edition, p. $267,1076 \mathrm{a}, 8$ note. 
cluded. So far as the objects of experience are concerned, it is evident that this is a world of the perishing. Yet even that which perishes attests that there is existence which is eternal.

It has been shown that from whatever point of view the matter is regarded, primal existence is essential if the other modes of being, such as quantity and quality, are to have a place in either thought or existence. The primal existence considered thus far has been exclusively that capable of being produced and likewise of perishing. Since it is perishable, and all other observable forms of existence have been found to be dependent upon it, there appears so far no reason why all existence might not be blotted out together. If there is such a possibility as this, the claim which philosophy makes to discover truth eternal and necessary is an idle boast. Before it may be called the highest and best science, something is needed, beyond the account of existence evident to sense.

Moreover, this account is as it stands incomplete. In the genesis of existences sensibly perceived it is impossible to admit an infinite regress. While the appearance of any new being is satisfactorily accounted for in the particular terms of what was antecedent to it, the whole series of generations is not thus explicable. 
The existence of the perishable necessarily implies existence which is imperishable. Whatever is perishable has arisen out of material; potentiality is a part of its nature. As it will cease to be, so it might never have existed at all. A permanent order of perishable existences obviously requires the existence of that which is eternal. In the last chapter of Book Kappa Aristotle has shown that the distinction between the perishable and the imperishable is an essential one. It cannot be a merely accidental trait that a particular existence is perishable; for an accidental quality is sometimes present and sometimes absent. Were it accidental that an existence is perishable, sometimes it would not be perishable, and all distinction between the mortal and the immortal would with that be obliterated. It is necessary to recognize that the imperishable is a kind of existence essentially different from the perishable. Through the failure to appreciate this truth the doctrine of Ideas has fashioned eternal existence upon the same lines as what is perishable. The Ideas are only shadowy copies of what perishes. The historical prestige of the doctrine of Ideas has, however, been so great that in developing a theory of primal existence not evident to sense, this with the related doctrine of mathematical entities cannot be left without a thorough 
investigation. In practice, Aristotle says, these doctrines are not always distinct, but he finds it desirable to examine each separately. ${ }^{1}$

II

In order to show that mathematical existence rightly conceived is merely an aspect of existence evident to sense, 'Aristotle demonstrates that the supposed mathematical entities ${ }^{2}$ can neither exist absolutely in objects nor can they exist wholly apart from them. The mathematical solid, for instance, cannot be thought to reside in any actual body; first, because two solids cannot be in the same place; secondly, because if the mathematical solid were conceived to be in the object, there would result an absurd heaping up in this of numerous surfaces, lines and points-some, mathematical, others, objective; finally, since the mathematical solid is conceived to be indivisible, the object with

${ }^{1}$ Whether numbers, points, lines and figures could be considered primal existence, made one of the perplexities of Book Beta, and has been a problem occasionally approached in the succeeding books. More frequently the discussion has led to questions concerning the validity of the theory of Ideas. But it is not until Books $\mathrm{Mu}$ and $\mathrm{Nu}$ are reached that there is opportunity for a sys- . tematic inquiry into the two doctrines.

${ }^{2} \tau a \grave{a} \mu a \vartheta \eta \mu a \tau \iota \kappa a ́$. 
which it is supposed to be coterminous would also be indivisible. If, on the other hand, the mathematical entities exist quite apart from what is evident to sense, there will be nothing to fix a limit to the creation of entities more and more remote from the concrete; nor would sciences such as optics, harmonics, mechanics, have any determinate objects of inquiry. It is evident that mathematical existence cannot be independent of the existence of bodies. ${ }^{1}$ An abstract science of magnitudes is possible, just because it is directed to the consideration of an aspect of bodily existence. Similarly there may be scientific formulations concerning the weight of bodies and concerning their motion, but neither weight nor motion can be said to exist in isolation. Numbers, lines and figures are as little qualified for independent existence as are motion, color, sound.

The doctrine of the Pythagoreans attempts nevertheless to explain all existence as derived from numbers. Aristotle finds it desirable in the consideration of a view of this nature to distinguish between the various forms in which it may be advanced. Number, regarded not as number of something, but as itself an independent

${ }^{1}$ In concept the mathematical may be prior, but in point of fact there can be no magnitudes independent of existences sensibly perceived. 
existence, may be viewed as made up of units all alike or all essentially different from one another; or as composed of groups of like units, which are in every case unlike the units of other groups; or finally as composed partly of units which are so differentiated as to belong in groups and partly of undifferentiated units. Aristotle describes with some detail the existing divisions of the schools, then undertakes to find whether the units which enter into numbers are properly regarded as all alike or as different. A special inquiry is directed towards each view, and the conclusion reached is that it is absurd to regard the units of number as unlike in kind.

It follows that if the existences we know were dependent upon some eternal existence conceived as of an essentially numerical nature, whether as simple number, square or cubic, many of the diversities which undoubtedly exist would not appear. If the units of different numbers are all like in kind, an explanation in terms of number would have to overlook important differences. Nor would it at all adequately account for such existence as it attempted to explain. It is said, for example, that seven are the vowels, seven the harmonic chords, seven the stars of the Pleiades, at seven years certain animals shed their teeth, and seven 
were the heroes against Thebes. But it is not from the existence of the number seven that these diverse facts, with which this number chances to be connected, have their reality. Numerous other coincidences, whence the fantastic doctrine of number seeks to elicit truth profoundly philosophic, have given occasion to the followers of Pythagoras for neglecting great and significant distinctions; and the result has been that their theory has built upon the accidental.

\section{III}

If the doctrine of the Ideas is considered genetically its kinship with that of mathematical entities is at once apparent. Without the formation of concepts of wide applicability it is impossible for thought to progress. ${ }^{1}$ The forms which repeatedly appear under ever shifting conditions may come to be regarded as independent existences remaining in permanence through all the muta-

1 It was probably Socrates who first became keenly aware of the great importance, for effective thinking, of arriving at sound definitions. His interest in universals did not, however, lead him to attribute to them independent existence. It was rather under the influence of Heraclitean teachings, as Aristotle has recounted in early passages, that appeal was made to the universals in order to escape the seeming flux of all particular existence. 
tion of sense. Just as was done in the case of number and the mathematical generally, the universal, which exists only as realized in concrete individuals, is made an independent and primarily real being, whence the existence of concrete individuals is derived. This done, there is no adequate explanation of such derivation, since the universals are conceived supposedly as unsubstantial verities, while the reality of other existence is discredited. Aristotle says that the advocates of the Ideas are like those who in order to count a very large group of objects might think to make the task less difficult by adding to the objects present a great many more of similar character. His specific objections to the doctrine may be grouped under two heads: those which are directed against the lack of any definite standard according to which the Ideas may be assigned as causes of certain kinds of existence and not of other kinds; and those which are directed towards the futility of the Ideas for explaining that of which they are in some way the cause.

Why, in the first place, should there be Ideas for that of which there is affirmation, and not for negations as well; why for existent beings, and not also for objects now d estroyed, since of the latter there remains at least the concept; why only for independent beings, 
and not for that existence which is merely relational?

It is to the relational that universals are most extensively applicable; yet the-Ideas are all regarded as primal existences. ${ }^{1} \quad$ Properly universals as such belong to knowledge; all existence is individual. Demonstration requires statement that is general; yet its results always have particular application, as the concepts upon which it has proceeded have been formed from knowledge which always has a particular reference.

The manner in which perishable beings could be related to the changeless Ideas is a problem which Aristotle believes no one can solve or even state clearly. It is said for example that the Ideas are the exemplars of the beings of this world, and are thus cause of existence and of change. But it is even admitted that in the production of many common objects they have no part; and as regards the rest a mode in which they might have any genuine influence is inconceivable. ${ }^{2}$ Now it is possible for something in existing or being produced

${ }^{1}$ It is easier on such a hypothesis to suppose that the transitory and relative existence can participate in the Ideas.

'It is noticeable in Aristotle's criticism that he shows no inclination to give to the doctrine of Ideas so much consideration as his indebtedness to it for his own theory of form would appear to require. 
closely to resemble something else with which it has, nevertheless, no actual relation; the greatest failure of the doctrine of the Ideas appears to be its neglect to say what it is which works up ephemeral existence in fidelity to the eternal Ideas. Aristotle's conclusion is that the Ideas, just as the mathematical entities, are abstractions from actual concrete existence, justifiable and desirable for certain purposes, but productive of much unclear thinking when erected into independent original existence. 


\section{CHAPTER VIII}

\section{Divine Existence}

I

IT is impossible to suppose that at a definite point in time existence began and before that was not. Aside from Aristotle's inclination to regard existence as not merely accidental-which naturally results from his conception of philosophy as the inquiry into necessary truth-the analysis of existence evident to sense has brought out an urgent reason that for all the established way of nature there should be recognized a more ap= propriate cause than that of a mere possibility for being as it is. . It is not difficult to show that the world process as a whole is not transitory; the beings which enter into it are ephemeral, but the process itself can be demonstrated to be eternal. There was, Aristotle argues, no time when change was not, since time itself is bound up with change ${ }^{1}$ - and clearly there was no

${ }^{1}$ Cf. 1071b, 10 .

(167) 
time before which time was not. Equally inconceivable is the cessation of change. Change is then eternal. But if change is eternal, there is nevertheless no uncaused change. If one assumes merely that there was a primordial chaos out of which came a universe, there is no sufficient explanation of the source whence matter, which cannot move itself, received its impulse. It does not solve the difficulty to posit an eternal movement as Leucippus and Plato have done. ${ }^{1}$ If nothing is said as to how or why this movement exists and what it is, the statement is not complete, for certainly it does not originate in chance nor is it fortuitously directed.

The deficiency is not supplied by the doctrine of the Ideas, for the Ideas are passive and devitalized entities; and moreover they stand in the way of a clear understanding of what takes place in the observable world. It has been found that every primal existence throughout the range of our experience has come from what is itself particular, and neither needs nor can make use of a universal as exemplar. But it has also been demonstrated that the perishable beings known to sense require an . existence of a superior nature. It is not reasonable that the uncounted generations, the 
ceaseless exchange of the old-formed matter for the newly formed, be viewed as extending back in an infinite past, with ever an earlier shape dimly beyond, accounting for its successor and in turn dependent on its infinitely many forerunners. Repugnant as is the infinite regress.to all of Aristotle's thinking, it is nowise acceptable in statement of the world process. It is.an offence against reason more harshly to be condemned, because more insidious, than the naïve account that out of chaos and the abyss sprang Earth and Light, the two first parents. But the latter view, too, with others of its kind, has an irremediable fault. Even when such an account of first genesis receives the garb of reflection, and in their endeavor to be scientific, thinkers believe themselves to have arrived in imagination at a point where there is as yet no creation but only the bare possibility of it, either nothing or an absolute chaos, reason's most urgent demand is ignored.

That there must be an eternal being as origin of the eternal movement is a truth which a final account of existence cannot overlook. Just as in the realm of human experience there is always some cause of movement-nature, mind or other force-the origin of world movement must have been and must be a First Cause, an Unmoved Mover. 
The First Cause must also be viewed as ever active, for had it the power to become quiescent, were potentiality a part of its nature, nothing would prevent the annihilation of all the world that is. And similarly, - had there ever been a mere potentiality that the world should be, its eventual realization would not have had in its favor even a higher degree of probability; the world might as well have failed to be. If reason have dominion, the world existence is no mere chance happening, but is necessary, in that it must be what it is; since were it otherwise, it could as readily not have been at all. Viewing the world existence as in this sense necessary, Aristotle has herein another justification for the belief that it has a determinable cause, which chance existence would not have. Also, in the conclusion that the cause in no way partakes of the potential, he has a motive for ruling out from the nature of the cause all that is material and all the attributes of material existence.

\section{II}

Having in its nature nothing that is material, the first cause cannot be an efficient cause. It is impossible that the world change is transmitted from the eternally active cause in any mode resembling that in which 
one body impels another. That which operates as efficient cause itself moves; and how conceive the motion of that which is devoid of matter ?' Efficient causation may appear in varied guise, but essentially it is always the operation of a moving body. Limited to such terms an account of world change could never be ultimate. It might extend far, but if it had no auxiliary concept for the origin of motion, it would not be adequate even so far as it went; and it would terminate inconsistently in that which did not move-or more unhappily in infinite regress, for always one body would receive its altered motion from another body, and that which for a moment seemed a first cause would demand still another beyond it, and so on without end. Of course it might be supposed that somewhere there arose spontaneously a body which should move the other bodies, or that at various points there were uncaused alterations in existing motions; and that thus the present scheme of change was made. Such a view, however,

${ }^{1}$ Moreover that which moves may at some moment be considered to have only the potentiality of at least a part of the motion-since any motion requires time. Clearly the first cause does not impart movement in the same manner as does an efficient cause; for assume that it did, it would no longer be the first cause, but prior to it would be another cause. 
would endow the process as a whole with a character predominantly fortuitous, and hence is adverse to Aristotle's earlier reasoning as well as uncongenial to one who finds the universe both ordered and truly alive. Explanation by efficient causation Aristotle regards as appropriate in the restricted field of natural science, which, though ideally complete, could never replace philosophy, simply because, dealing with that which is material, it cannot without exceeding its province discover the non-material first-cause of motion.

If not efficient the original cause of motion is then not in itself motion nor in motion. At the same time it cannot be the quiescent, mere passivity. It does not operate as efficient cause and yet is somehow responsible for the great world change.

Now, movement can be caused without any movement on the part of that which causes movement only as the desirable and the intelligible cause movement; for these without undergoing any change impel movement. ${ }^{1}$ If not a compelling, disposing agency, a world artisan, the eternal must appear in the light of the Good. It is the Good which without entering into the contest yet determines what the result 
shall be. It is the Good, the final cause, which imparts motion otherwise than efficiently, which attracts, induces; which without exerting force dominates by its very excellence. It is the Good, moreover, which fulfils the other requirement of the first cause: the Good is form; it is fully actual, in nothing potential.

* The First Cause is then a final cause. Fundamentally the desirable is the intelligible, is form; for the desirable is that which appears good, and certainly an end is desired because it seems good, rather than does it seem good because it is desired. That is desired which the intelligence recognizes as good, and intelligence is moved by the intelligible. In being aware of the intelligible, intelligence has its complete actuality. The good and desirable is then fundamentally the intelligible, and the intelligible has its existence in intelligence. Accordingly that which is final cause-that which itself unmoved arouses movement as does the object of desire-exists intelligibly, and as completely actual is intelligence. ${ }^{1}$

But intelligence is life, since it is the activity of reason. As first cause, this life exists necessarily; and as first, it is best. It is activity, life in the completest 
sense of the word, perfect spirituality. The unmoved mover is then the eternal perfect living being, is God. ${ }^{1}$

Since the eternal is actual there was not originallyas say the "theologians" or the nature philosophersfor an unlimited time, night or chaos; but the same things have existed eternally, either in successive selfrepeating periods or continuously." To account for the eternal sameness of the world it is necessary that there be an eternal principle always active in the same way. But this is not of itself sufficient to account also for the continual diversity in the world. Aristotle finds it impossible to explain existence wholly with reference to an unchanging first principle. Such an explanation would have to find in the world nothing but manifestations of a single activity; all existence would be identified with that one existence. If diversity is to be admitted as genuinely present in the world, Aristotle argues, there must be a second principle which acts now in one way, now in another. ${ }^{8}$ A single principle cannot, however, be conceived as thus acting in different ways through inherent impulse. It operates in one way solely by its own nature; to account for the other mode of operation one must assume that it is acted

$$
{ }^{1} 1072 \mathrm{~b}, 27-30 . \quad 21072 \mathrm{a}, 8 . \quad 1072 \mathrm{a}, 11 .
$$


upon by a principle outside of itself. Is it then necessary to conceive a third principle which influences the second? By the above hypothesis the first principle is the explanation and the cause of sameness in the world; and since this precedes the diversity, it is clear that one need not posit a third principle to explain the eternal diversity.

The interpretation of this result of Aristotle's general inquiry into what will constitute adequate explanation seems to be that matter and form must both enter into the constitution of the universe and that they together suffice. Matter is aroused by form and this makes the eternal sameness of change; but matter has a nature of its own, is sometimes inert, refuses to be acted on by form, is only partially adaptable; and hence the diversity. It is through the existence of both form and matter that there is an eternal change which is orderly and yet permits variation.

No merely vague and general good, the result of many lesser goods, not simply an observable world tendency in the right direction, at all satisfies the requirements of Aristotle's thought. It is as essential that there be a definite, wholly actual, individual existence, which is good, and prior to all world change, as it is obvious that there is world change. Aside from the specific reasons 
offered in support of this view, it appears wholly irrational that there be any process, much less an orderly development, if it is not in view of a good to be achieved, that is, a form to be embodied. The alternative is shown to be a mechanical theory, essentially incomplete or ineffectually resorting to chance. Now, the admission of chance to a limited domain is the means whereby Aristotle is enabled to preserve for his own view a due recognition that the world is not throughout a pre-adjusted harmony, with nothing however trivial undetermined, with no emergencies. But this is very different from viewing the whole career as one of chance, or predominantly so. Such an exaltation of the fortuitous is not only rejected from Aristotle's final account of existence, but is regarded by him as hostile to every philosophic endeavor. It is in its very conception antagonistic to knowledge.

Intimately related to the denial that chance is in any way present at the origin of the world order is the repeated assurance that the first cause is completely actual, without trace of potentiality. ${ }^{1}$ When one passes

2 The general doctrine of the primacy of the actual, which appeared in Aristotle's earlier discussion, has the same logical basis; and so far as its emphasis exceeded the requirements of the empirical study, may be regarded as anticipatory of the inquiry into changeless being. 
from the consideration of things changeable to the realm of the unchanged, the concept of potentiality falls quite away. Where there is no change there is of course no need for that whence altered existence may arise; but things are actually, immediately, unqualifiedly what they are. This does not mean that they are static, inert. Rather they are in that complete, that perfect activity, which knows no weariness, meets no obstacle -which is eternal attainment, with no shortcoming. It is only in guarding against a possible misapprehension of the kind of peace the eternal enjoys that the concept of potentiality may still by contrast have a value. It is the repose of perfect activity; and as such is in Aristotle's view complete happiness.

It remains only to make a more exact determination of what this activity must be conceived to be. Aristotle gives frequent indications even in the early part of the work that philosophy will attain its end only when it has become a theology. But the means by which it is so extended are developed in the course of the discussion of objects in ordinary experience.

III

It has been said that, standing in some unalterable relation with all change or itself perhaps an essential 
part of change, is time; that time is eternal, and with it change is eternal. Potentiality, accordingly, must be excluded from the conception of a continuous, exhaustless change, since the potential is that which either may or may not be. The only form of change that can be entirely continuous and free from even the slightest cessation is movement in space, and of this only that which describes a circle. ${ }^{1}$ Aristotle believes that the celestial sphere is revolved with unceasing uniform motion, and that for the sun, the moon and the other moving heavenly bodies, severally, astronomy may declare with more or less confidence various other eternal movements. For each of these he argues that there must be a mover eternally active, and that the number of the eternal actual existences is not greater than the number of eternal movements.

Beginning with the study of objects evident to sense and passing thence by the necessities of the argument to the acknowledgment of the eternally active, viewed - again by the requirements of the mode of reasoningas the final cause, and therewith the all-perfect, Aristotle retains in his "science of the divine" a remarkable fidelity to the facts of empirical observation. His conclusion concerning the plurality of divine existences ${ }^{1} 1072 \mathrm{~b}, 9$. 
and their relation to the perceived world is perhaps the most striking example of the importance which he attaches to empirical fact. The world movement as a whole he conceives to be one; and in the light of this he develops the theory of the one God. Besides the movement of the heavenly sphere there appeared also to be independent and more or less complex movements of the chief heavenly bodies. Influenced perhaps by immemorial belief and evidently by the astronomy of his day, Aristotle makes out an enumeration of lesser divinities in governance of the various celestial courses. This requires an excursus into astronomical theory, for he must determine how many independent movements there are. The result is a quaint addition to the general theory; but it must be remembered that at this period the advantages for noting relatively minute variations were not such as to suggest that the movements of the planets, though observably complex, are not eternally constant. In an age to which the now familiar conception of the subjection of even the heavenly bodies to the long process of generation and decrepitude was strange, such a study as this was apparently required in order to meet satisfactorily the demands of empirical fact. From the vantage point of the best empirical observation of the day, the concep- 
tion of a God who is one could hardly be the sole philosophic development.

It is, however, a conspicuous feature of Aristotle's study of the divine that he makes no attempt at coördinating the main result with the result which was incidental to the imperfect astronomical theory of the age. The enumeration of the lesser divinities is not only tentative-for he does not know just what account of the movements is to be "preferred-it is episodic. It is not brought into relation with the main development. There is no effort to indicate specifically the nature of the lesser divinities; and if it is to be inferred that their nature does not differ essentially from that of the First Mover, it is odd that no mention whatever is made of the correspondence. It is also strange that no question arises as to how several lesser first movers are in governance of a single body; true, each is requisite to explain one of the several movements which combine to produce the complex phenomenon, but no statement is made as to what relation, if any, exists among the movers. Most remarkable of all, however, is the failure to establish the relation subsisting between the lesser divinities on the one hand and the one God on the other. After the utter rejection of all ordinary modes of conceiving divine plurality, Aristotle might 
be expected to offer, as is his custom, some substitute for the view he condemns. It is fair to ask, when he has developed the theory of the star divinities, what more exactly their nature is; and if gods, what their relation to the supreme First Mover.

To a Greek mind such questions might have been more perplexing if religious tradition had not been what it was, and perhaps Aristotle, being a believer in the gods, saw no need for a more closely knit argument. At any rate he had firmly to believe that the courses of the planets were eternally the same, and as such they required by his system of thinking distinct and eternal movers. It is, however, worthy of note that the exposition regarding the nature of God is undertaken and brought to its conclusion quite as it would have been were there no admission of star divinities. The existence of the lesser divinities is merely stated as demanded by the argument, in view of recognized fact. But the enumeration is pursued as if the result were for philosophy an almost indifferent matter. With a somewhat indecisive conclusion the discussion is closed, not to be resumed.

The development of the attributes of the First Mover, on the other hand, receives an elaborate exposition, with every indication of fervency of interest and of a 
keen realization of its great philosophic importance. A ristotle repeatedly urges that God must be conceived as one. The significance attached to this doctrine, taken in conjunction with the very minor importance allotted to the star divinities and the conspicuous absence of any attempt fully to relate them with the general system of thought concerning the divine, indicates that had the observations of astronomy been more advanced, Aristotle, being no longer coerced by reputed empirical fact, would probably not have grieved at the elimination of that portion of his theory which relates to the lesser divinities. What, as the exposition stands, appears as a positive defect becomes in the light of present knowledge a negative merit. Had he attempted to bring the divinities of the stars into relation with the system, had he not left it as a detached recognition of that which a really defective empirical observation demanded, such modifications would doubtless have been made in the main theological doctrine that its vitality would have fallen away when the error of the empirical fact was discovered. But with the state of knowledge what it was, it is a credit to Aristotle that he made a place for the view as he did; and in our present state of knowledge equally a credit that he left it unattached, undeveloped. According to the strictest canons there 
is an inconsistency in the exposition. Aristotle's predilection is strongly in favor of a unitary conception of God. And so it is that-after a custom which has been dear to the writers of books - the text of Book Lambda, the crowning work of the Metaphysics, closes with a quotation of verse:

"Existences wish not to be misgoverned. Let there be one Sovereign!"

\section{IV}

The remainder of the theory concerning the divine is developed in a way which suggests that, for its author's thought, considerations of a physical reference have given place to a regard for the known facts of the moral and intellectual life. The divinities of the heavenly bodies are left with the comment that about their existence the myths of the gods have grown up. From this point interest centers in the conception to be formed concerning that primal existence whence proceeds the movement of the celestial sphere; yet with the exception that the name of First Mover is retained, the specific relation in which the necessity for the existence of the supreme being was originally presented disappears, although it remains firmly fixed in the argument that the relation of the divine being to the world is that 
of the unmoved mover of the eternal one movementgoverning not as overlord, but as the supreme form towards which all nature is drawn in desire for that which is perfect. From the existence of the First Mover, matter is necessarily excluded. That which is in any degree material partakes just so far of potentiality, and it is impossible that the mover of an eternal movement be other than completely actual.

In its dependence upon the concept of the completely actual, the exposition of the nature of the divine is rendered a very direct one, just as the earlier argument for the existence of the eternal was facilitated by the initial recognition, which followed upon the empirical analysis, of the primacy of the actual. An existence which is completely actual cannot be supposed to undergo modification of any kind. Yet a being whose life is thought must be supposed to be active, and if the divine intelligence is completely and continuously possessed of that perfect contemplation which human beings "rarely and for brief moments but partially enjoy," it must have some object of its thinking. The demands of the conception of the divine as changeless and as related to the world only as final cause, require the conclusion that the divine intelligence is occupied in self-contemplation. If the supreme being thinks, 
the thought must be not of any chance subject but of what is most divine and most honorable; if the object of thought is such, clearly it cannot change, since any change would be for the worse. The object of thought must then be the divine existence itself, and the thought is of thought; the activity of the supreme form can be considered as nothing else than self-activity.

The divine perfection is not, however, utterly removed from the natural world. Through the control of the supreme form order abides in the world of natural things and the harmony of diverse existence is established. That there is a cosmos results from the unity of the First Being. The thinkers who have posited several discrete first principles, such as a number of mathematical existences independent of one another, have done violence to the very conception of the universe.

As a result of the inquiry concerning what exists beyond the reach of sense, Aristotle has shown that that which exists eternally is in no way assimilable to what is transitory. It is not a generalized aspect of that which sense may perceive; it is not an abstraction; it is not an improved reduplication of any earthly being with added qualities of original might and eternity. It is a life, individual, fully active, moving the matter of 
the world not as by the creator's hand but as the supreme good, the form of the universe.

Thus has Aristotle crowned a masterpiece of exposition, beginning, it will be remembered, where our common knowledge ends, thence giving each step in detail, until he has produced a fully formed system. Nor is he less a master of demolition. It is, perhaps, as if several attempts had been made to bridge a turbulent stream. At last the expert engineer appears; he sees how materials have been misused, how the functions of beam and cable have been mistaken. $\mathrm{He}$ sees the structures of his predecessors fallen or impassable, and guided partly by their failures but mainly by his own clear plan, he rebuilds, strongly, with ample approaches. So Aristotle used materials at hand, most of which had been used before; but he placed them anew and firmly, and he built for the generations.

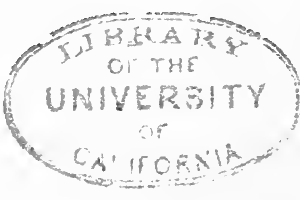





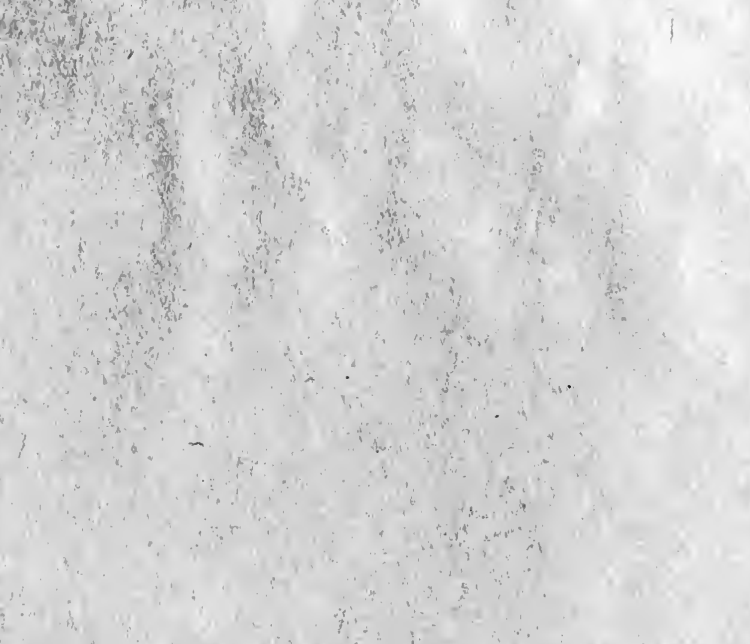


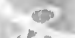

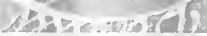

\section{DAY USE}

BETURN TO DESK FROM WHICH BORROWED

RFTIJRN

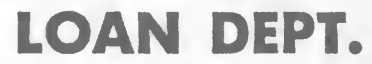

This book is due on the last date stamped below, or op she date to which renewed.

Renewed pooks are subjecto roliaje recall.

7 Jul'65J $(\mathrm{C})$

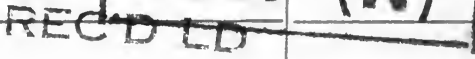

JUL 7'65-3PM

FEB $2319708 \mathbf{7}$

REC'D LD FEB? 2'70-4 BM

IEP 24

lc

1) RECD ID SEP 14 , W

FEB 231971

3

REC'D LD FFB $99^{\prime} \cdot-8$ PM 59

MAY 23197380

s

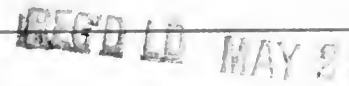

LD 21A-60m-3,'65

(F2336s10) 476B

General Library

University of California Berkeley 
